University of Louisville

ThinkIR: The University of Louisville's Institutional Repository

Electronic Theses and Dissertations

$12-2014$

\title{
Lunasin reduces the melanoma stem cell population in vitro and inhibits tumor proliferation in vivo.
}

Christopher Paul Shidal

University of Louisville

Follow this and additional works at: https://ir.library.louisville.edu/etd

Part of the Pharmacy and Pharmaceutical Sciences Commons

\section{Recommended Citation}

Shidal, Christopher Paul, "Lunasin reduces the melanoma stem cell population in vitro and inhibits tumor proliferation in vivo." (2014). Electronic Theses and Dissertations. Paper 1765.

https://doi.org/10.18297/etd/1765

This Master's Thesis is brought to you for free and open access by ThinkIR: The University of Louisville's Institutional Repository. It has been accepted for inclusion in Electronic Theses and Dissertations by an authorized administrator of ThinkIR: The University of Louisville's Institutional Repository. This title appears here courtesy of the author, who has retained all other copyrights. For more information, please contact thinkir@louisville.edu. 
LUNASIN REDUCES THE MELANOMA STEM CELL POPULATION IN VITRO AND INHIBITS TUMOR PROLIFERATION IN VIVO

\author{
By \\ Christopher Paul Shidal \\ B.S., University of Kentucky, 2008

\begin{abstract}
A Thesis
Submitted to the Faculty of the School of Medicine of the University of Louisville In Partial Fulfillment of the Requirements
\end{abstract} \\ For the Degree of \\ Masters of Science \\ Department of Pharmacology and Toxicology \\ University of Louisville \\ Louisville, KY
}

December 2014 



\title{
LUNASIN REDUCES THE MELANOMA STEM CELL POPULATION IN VITRO AND INHIBITS TUMOR PROLIFERATION IN VIVO
}

\author{
By
}

Christopher Paul Shidal

A Thesis Approved on

October 30, 2014

By the following Thesis Committee:

Keith R. Davis, PhD- Thesis Director

J. Christopher States, PhD

Brian P. Ceresa, PhD

Kavitha Yaddanpudi, $\mathrm{PhD}$

Geoffrey J. Clark, PhD 


\section{ACKNOWLEDGMENTS}

I would like to thank my mentor, Dr. Keith R. Davis, for his guidance during this period. I would like to acknowledge Dr. Kavitha Yaddanpudi for her help on this project. I would like to thank the committee members who agreed to serve on my graduate committee and offered invaluable advice and support throughout this process. The University of Louisville, IPIBS, Dept. of Pharmacology and Toxicology, Owensboro Grain, and The Helmsley Charitable Trust for providing the necessary funds and equipment needed for completing this project, thus I owe much gratitude to these entities. 


\title{
ABSTRACT \\ LUNASIN REDUCES THE MELANOMA STEM CELL POPULATION IN VITRO AND INHIBITS TUMOR PROLIFERATION IN VIVO
}

\author{
Christopher P. Shidal
}

October 30, 2014

Lunasin is a 44 amino acid peptide derived from the soybean seed that has been shown to have cancer chemopreventive and chemotherapeutic properties. In this study, we investigated the potential utility of lunasin as a chemotherapeutic in a melanoma model. Initial studies showed that lunasin has little activity against established melanoma cell lines in vitro using adherent culture methods; however, lunasin's in vitro activity was significantly higher in non-adherent colony-forming assays in soft agar and oncosphere assays. These results led us to investigate whether lunasin selectively affects cancer initiating cells (CIC) that are known to be present in these melanoma cell lines. We found that lunasin treatment did selectively inhibit the proliferation of high-ALDH-expressing malignant melanoma initiating cells (MMIC) in vitro, and had the striking effect of preventing oncosphere formation under non-adherent culture conditions. These in vitro results were extended into mouse xenograft studies using both bulk melanoma cells and isolated CICs. Lunasin significantly inhibited tumor growth in both cases, with the highest inhibition being observed in tumors initiated by MMICs. Mechanistic studies suggested that lunasin inhibits CIC proliferation in vitro through interactions with 
integrins and disruption of integrin signaling by inhibiting the activity of integrin binding partners such as integrin-linked kinase (ILK) and focal adhesion kinase (FAK). These studies demonstrate for the first time that lunasin has activity against putative CICs and that lunasin may have utility as a therapeutic agent for the treatment of melanoma. 
TABLE OF CONTENTS

PAGE

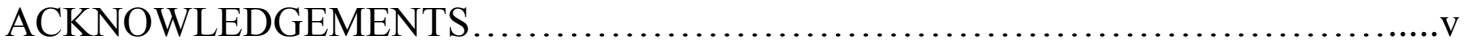

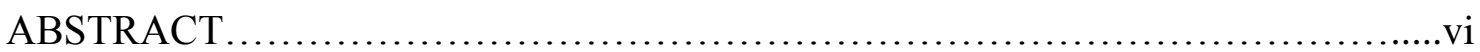

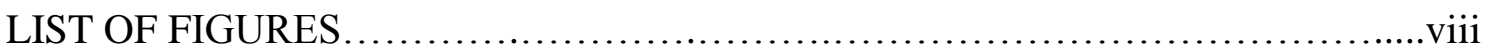

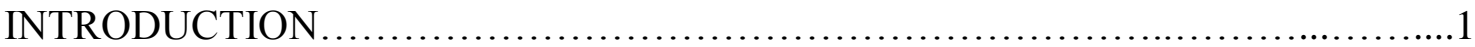

Profiling the Soy-derived Peptide Lunasin as an Anticancer Therapeutic...........1

Integrins as a Targeted Therapy in Melanoma Patients............................4

Melanoma and the Presence of Melanoma Stem Cells............................

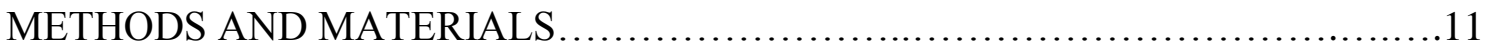

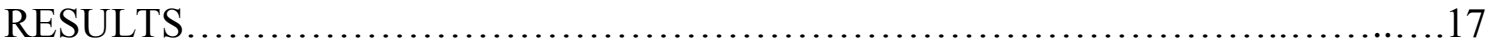

In vitro Effects of Lunasin on Established Melanoma Cell Lines..................17

In vitro Effects of Lunasin on ALDH Sorted Melanoma Cells.....................20

In vivo Xenograft Models for Bulk and Sorted Tumor Samples....................25

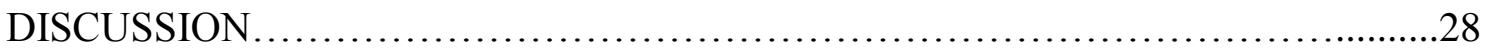

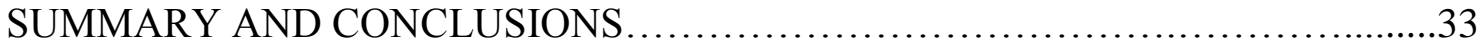

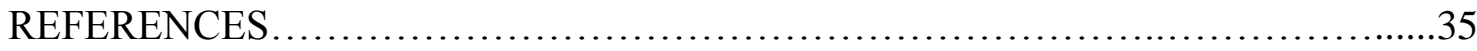

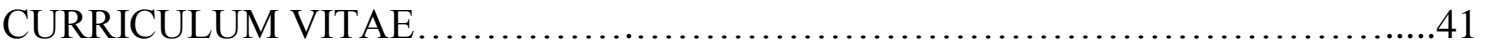




\section{LIST OF FIGURES}

FIGURE

PAGE

1. Lunasin Inhibits HAT Binding to Core Histones............................42

2. Integrin Signaling through FAK and ILK................................ 43

3. Fluorescence Assisted Cell Sorting Based on the ALDH Biomarker................44

4. Proliferation Assays of Melanoma Cell Lines................................45

5. Colony Formation in Soft Agar...........................................46

6. ALDH Staining of Melanoma Cells Treated with Lunasin and Vemurafenib.........47

7. Representative Histogram for Lunasin Treated A375 Cells......................48

8. Flow Cytometry for ALDH in Lunasin Treated Samples...........................49

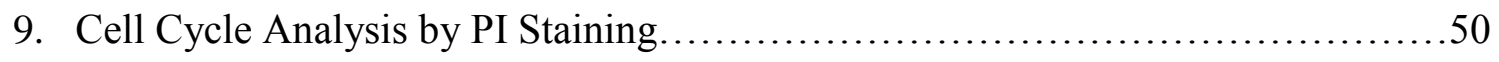

10. Annexin V Binding Assay for Melanomas Treated with Lunasin and Vemurafenib....................................................... 51

11. Apoptotic Profiles of Melanomas in Response to Lunasin Treatment..............52

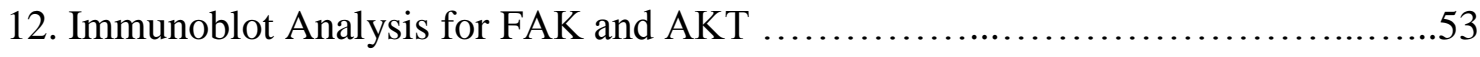

13. Oncosphere Formation in Low Adherent Conditions .............................54

14. ALDH Positive Cell Growth as Colony Formation in Soft Agar ...................55

15. Xenograft Model for A375 Melanoma Cells (IV Injection)......................56

16. Xenograft Model for A375 Melanoma Cells (IP Injection).......................57

17. NSAID Toxicological Screen and CBC for Safety of Extended Lunasin

Treatment...........................................................58 
18. Xenograft Model for ALDH Positive Melanoma Stem Cells......................59 


\section{INTRODUCTION}

\section{Lunasin as an Anticancer Agent}

Lunasin is a soy derived peptide that has demonstrated anticancer, antiinflammatory, antioxidant, and immunomodulatory activity [1-4]. Lunasin has been reported as a 43 amino acid fragment present in processed $2 \mathrm{~S}$ albumin protein [5]; however, we recently identified a native 44 amino acid sequence of lunasin isolated from defatted soy flour consisting of the sequence:

\section{SKWQHQQDSCRKQLQGVNLTPCEKHIMEKIQGRGDDDDDDDDDN [6]. Lunasin} has been proposed to have three distinct domains that are responsible for its therapeutic and chemopreventive activity: an RGD sequence involved in internalization of the peptide via integrin binding, a poly-aspartic acid tail that binds lysine residues present in $\mathrm{H} 3$ and $\mathrm{H} 4$ histone tails, and a hypothesized chromatin binding domain [7, 8]. Limited studies describe the direct chemotherapeutic effects of lunasin against cancer as it is generally defined as a chemopreventive agent based on earlier studies by de Lumen and coworkers [7, 9-12]. Thus, many questions remain about the number of cancer types sensitive to lunasin, the possible mechanisms of lunasin's anticancer effects, and to what extent lunasin is involved with the tight correlation of soy consumption with a protective effect against certain cancer types [13-15].

Lunasin has been found to inhibit transformation induced by multiple carcinogens and viral oncogenes $[7,9,16-18]$. Moreover, studies in our lab indicate lunasin is able to inhibit transformation of mouse fibroblast cells induced by carcinogens present in 
cigarette smoke including cadmium and nicotine-derived nitrosamine ketones (data not shown). The most discussed mechanism of action of lunasin is the inhibition of histone acetyltransferases (HATs) and modulation of histone acetylation.

The acetylation of core histones initiates the unwinding of tightly packed DNA from the nucleasome complex allowing for transcription of target genes (Figure 1). HAT inhibition alters normal acetylation patterns leading to hypoacetylation of histone tails, repressing transcription and can account for global cellular effects including proliferation, cell cycling, and apoptosis [19-21]. Although some evidence supports HAT inhibition as lunasin's primary mechanism of action, to date, there have been no functional studies to support this hypothesis. Moreover, as new principal mechanisms of lunasin action are still being discovered, it is not clear in the different experimental systems that have been studied whether histone acetylation is involved in all cases.

Studies in our lab confirm a significant antiproliferative effect of lunasin on nonsmall cell lung cancer (NSCLC), an effect which is mediated by disrupting cell cycle signaling (McConnell, 2014). Previous studies have acknowledged that lunasin reduces cyclin-dependent kinase (CDK) levels, and may accommodate aspirin-induced apoptosis in breast cancer models [22, 23]. Additionally, lunasin was reported to induce apoptosis and alter expression of matrix adhesion proteins in metastatic colon cancer [24]. Lunasin was recently shown to suppress FAK/ERK/NF- $\mathrm{kB}$ signaling in human colon cancer as well as potentiate the antiproliferative and antimetastatic effects of oxaliplatin [25].

Sadly, many plant-derived compounds (e.g. curcumin) are quickly metabolized or excreted resulting in poor bioavailability, however, lunasin is active and bioavailable in humans consuming physiologically relevant amounts of soy [26]. In this study, 
volunteers were orally dosed with lunasin $(155.5 \mathrm{mg} /$ day $)$ in 50 grams $(\mathrm{g})$ soy protein for 5 consecutive days. De Mejia et al. revealed lunasin is orally bioavailable; however, incomplete GI absorption resulted in a low concentration $(71.0 \mathrm{ng} / \mathrm{mL}$ or approximately14 $\mu \mathrm{M}$ ) lunasin in plasma samples [26].

Prior studies suggest that lunasin interacts with a specific subset of integrin subunits, as supported by a 2012 study by De Meija and coworkers [2]. Furthermore, recent studies suggest that internalization of lunasin is mediated by $\alpha_{v} \beta_{3}$ integrins via clathrin and caveolin-mediated endocytosis [27]. Proximity ligation assays (PLA) verify that the specific integrin subunits $\alpha_{v}, \alpha_{5}, \beta_{1}$ and $\beta_{3}$ network with the lunasin peptide (Inaba and Davis, unpublished data). In normal cells, integrins mediate cell-cell and cellmatrix adhesions by recognizing binding motifs (i.e. RGD) as well as cooperating with growth factor receptors to induce proliferative and survival signaling [28, 29]. The ubiquitous nature of integrin signaling provides an interesting target for cancer prevention and treatment because many of these pathways are deregulated in cancer and result in uncontrolled proliferation and metastasis. More specifically, we are interested in elucidating the effects of lunasin treatment on downstream pathways associated with integrin signaling and how disrupting these pathways can therapeutically benefit melanoma patients. 
Integrins as a targeted therapy in melanoma patients

Integrins are vital to most cellular processes, and remain an important and underexplored target for cancer therapies. Recent studies utilizing RGD peptides have shown targeting of integrins as a viable treatment alternative in melanoma therapy by inhibiting tumor angiogenesis, growth, and metastasis [30-32]. Integrins are heterodimeric membrane proteins primarily implicated in cell adhesion and migration $[33,34]$; yet, integrins have also been reported to be intimately involved in cell growth, differentiation, and survival $[35,36]$. Two families consisting of $18 \alpha$-subunits and $8 \beta$ subunits comprise the 24 heterodimeric proteins known in humans [37], combined with complex conformational states and overlapping ligand specificities, make integrin signaling flexible yet highly intricate [38]. Furthermore, integrin expression profiles are largely dependent upon two dimensional (i.e. adherent conditions) adhesion versus three dimensional (i.e. non-adherent) adhesion [39], and can result in recruitment of very different subsets of proteins. Proteins attracted to different adhesion structures (e.g. paxillin) can produce diverse yet specific signaling cascades.

By categorizing NSCLC lines based on integrin expression profiles, we associated explicit integrin subunits with lunasin sensitivity (McConnell and Davis, unpublished data). Moreover, we showed lunasin exerts its anticancer effects in NSCLC by reducing activating phosphorylations of v-akt murine thymoma viral oncogene homolog 1 (AKT), Focal adhesion kinase (FAK), and interactions of $\beta$-subunits with integrin-linked kinase 
(ILK), thereby altering signaling pathways downstream of integrin-ligand binding (unpublished data).

In melanoma models, the integrin $\alpha v \beta 3$ is currently the predominant target for therapeutic applications of integrin antagonists. Integrin $\alpha v \beta 3$ is expressed at low levels in non-transformed epithelial cells relative to melanoma cells [40], as $\alpha v \beta 3$ expression has been related to metastatic potential and dissemination of melanoma neoplasms to a metastatic phenotype [41, 42]. Crosstalk between integrins and growth factor receptors has been well documented $[43,44]$. Enhanced cancer cell survival has been attributed to a number of interactions between integrin signaling and other pathways including increased BCL-2 expression, PI3K-AKT activation, or NF- $\kappa \mathrm{B}$ signaling [45-47]. We predict that lunasin binds $\alpha v \beta 3$ integrins through its RGD domain and inhibits proproliferative and prosurvival signaling.

Certain integrins have specific roles in melanoma; for instance, it has been shown that $\alpha_{4} \beta_{1}$, a homing molecule on leukocytes that binds VCAM-1, is absent on melanoctyes, yet present in melanoma cultures [48]. Consequently, $\alpha_{4} \beta_{1}$ may help melanomas mimic hematopoietic cells by enabling melanoma migration into tissues that express sing VCAM-1 [49]. Other integrins implicated in melanoma are $\alpha_{3} \beta_{1}$ and $\alpha_{5} \beta_{1}$, which were elevated in metastatic melanoma tissue. Furthermore, $\alpha_{1} \beta_{1}, \alpha_{2} \beta_{1}$ and $\alpha_{6} \beta_{1}$ integrin subunits were found to be reduced in metastatic versus primary melanoma [48].

Roles of integrins in CICs are somewhat ambiguous. Recent studies show that integrin subunits may be a viable marker for CICs and are responsible for stem cell pool maintenance and differentiation mediated by FAK $[50,51]$. CICs are proposed to be more tumorigenic based on properties such as chemoresistance, immune evasion, and 
self-renewal capabilities [52, 53]. Cilengitide (Merck Co.), a cyclic RGD (cRGD) peptide, has been used to treat glioblastoma and is the first integrin inhibitor to be used in Phase III clinical trials [54]. By selectively targeting melanoma stem cells and altering integrin signaling, we may provide a novel treatment for malignant metastatic melanoma. Furthermore, targeting of integrin subunits explicitly expressed on cancer cells may represent a dynamic solution to reducing off-site, adverse side effects generally seen with traditional chemotherapy. 


\section{Melanoma and the presence of melanoma stem cells}

Skin cancers account for nearly half of all diagnosed cancer cases in the United States and have increased in frequency over the last thirty years [55]. Melanoma is estimated to account for 76,000 new cancer cases in 2014 [56]. Despite being less frequent than other skin cancers, nearly $75 \%$ of skin cancer deaths are attributed to melanoma [56]. Even more unnerving, NCI's Surveillance, Epidemiology, and End Results (SEER) program estimates cases of melanoma have nearly tripled in the past thirty years increasing from 7.9 (per 100,000) in 1975 to 22.7 in 2011, while 5-year survival rates remain constant. Early detection and diagnosis is paramount for overall survival with 5-year survival rates of $98 \%, 62 \%$, and $16 \%$ for localized, regional, and distant diseases, respectively [56]. Continued research of melanoma has provided several "cracks in the armor" of metastatic melanoma leading to the development of several targeted therapies that aim to inhibit proliferation, metastasis, and angiogenesis of primary and secondary tumors. One such targeted therapy is vemurafenib, which decreases melanoma cell viability and proliferation resulting in tumor regression and increasing overall mean survival time [57, 58].

Vemurafenib targets a mutated form of the B-Raf protein found in approximately $60 \%$ of melanomas in which a V600E substitution leads to constitutive Raf signaling within the mitogen-activated protein kinase (MAPK) cascade [59]. In the majority of patients harboring this mutation, mean survival time has been improved with vemurafenib; however, after initial tumor regression, many patients experience 
recurrence of tumors that are vemurafenib-resistant [60-62]. Conferred resistance to vemurafenib may occur through a number of mechanisms including, but not limited to, feedback activation of epithelial growth factor receptor (EGFR), upregulation of other Raf proteins, or upregulation of N-Ras [62-64]. Our present studies focus on developing lunasin as an adjuvant therapy to targeted therapies such as vemurafenib. We found that lunasin interacts additively with vemurafenib to reduce the ability of melanoma cells to proliferate and form oncospheres in vitro, and may sensitize cell lines with acquired resistance to subsequent vemurafenib treatments via inhibition of PI3K/AKT signaling (data not shown).

One explanation for the reformation of palpable tumors with chemoresistance is the presence of CICs within the bulk tumor population. The presence of CICs and their origin have become a topic of debate [65-69]. According to the cancer stem cell (CSC) theory, a subset of cells within the tumor population have properties that resemble physiological stem cells including the ability to self-renew while also giving rise to daughter cells that differentiate to reform heterogeneous tumor populations [65]. In this study, we will show that CICs exist within bulk tumor populations at a relatively high rate, and that this subset of cells displays enhanced tumorigenicity.

Discovery of melanoma cells with stem-like plasticity was initially found in patient tumors overexpressing CD20 and CD133 [70, 71]. CD20 is a membranespanning surface molecule generally found on B lymphocytes; per se, it is the molecular target for monoclonal antibodies (e.g. rituximab) for treatment of select leukemias and lymphomas. CD133 (also called prominin-1) is a novel, membrane-spanning protein of no known function that is classified as a marker for primitive hematopoietic and neural 
stem cells. These subsets of cells were found to have properties of stem cells as well as enhanced ability to form palpable tumors in immunodeficient mice. Ensuing studies verify ATP-binding cassette sub-family B member 5 (ABCB5), a drug transporter playing a key role in chemoresistance, and Low-Affinity Nerve Growth Factor Receptor (LNGFR/CD271), a member of the tumor necrosis factor (TNF) receptor family involved in survival and differentiation of neurons, as viable MMIC biomarkers [53, 72]. However, scientists are slow to embrace this concept for a number of valid reasons. One concern remains the standardization of techniques for identifying and propagating cancer stem cells. Serial dilution and transplantation of CICs into NOD/SCID mice has long been the gold standard for determining stem cell populations; however, spheroid assays in addition to genetic lineage tracing provide in vitro assays for CIC classification [66].

To make matters more complicated, some evidence supports plasticity of differentiated cancer cells in a breast cancer model [73]. By reverting to a dedifferentiated phenotype, stem-like cells arise de novo in response to environmental cues [73]. These data support the theory of bidirectional movement between stem and non-stem compartments, and have serious implications on the plasticity of cells in cancer models as well as subsequent therapeutic strategies.

Although populations of stem-like cells are recognized in melanoma cell lines, the frequency of these cells is highly variable, ranging from less than $1 \%$ up to nearly $25 \%$ $[53,74]$. The incidence of cancer stem cells seems dependent upon the in vivo model, the biomarker used for identification, and the tumor microenvironment $[49,75]$. Conflicting reports indicate that tumor samples enriched for MMIC markers have enhanced tumor forming capacity. Quintana [74] showed tumorigenic cells are phenotypically 
heterogeneous in melanomas, as significant in vivo tumor growth was marginal based on select CSC biomarkers. Despite these findings, numerous studies report superior tumor forming capabilities of cells enriched for melanoma stem cell biomarkers including ABCB5 [76], CD133 [71], CD271 [72], and ALDH [77].

Aldehyde dehydrogenase (ALDH) is a family of detoxifying enzymes responsible for metabolism of certain alkylating agents such as cyclophosphamide. Enrichment for melanoma intiating cells by intracellular ALDH staining has come with mixed reviews; however, most evidence supports ALDH as a MMIC biomarker [77-80]. ALDH expression has also successfully been used to detect CICs in breast and colon cancer models [81, 82]. In this study, we implement a commercially available ALDH detection kit to identify and sort melanoma cells expressing elevated levels of ALDH from ALDH negative fractions.

Unfortunately, current therapeutics heavily rely on efficacy against bulk tumor cells and the ability of the drug to reduce primary or secondary tumor size. We suggest that lunasin specifically targets MMICs and reduces this aggressive subpopulation of cells. We are currently elucidating mechanisms for this effect, but believe lunasin treatment may induce terminal differentiation of cancer stem cells, inhibit self-renewal capacity, or alter integrin signaling leading to antiproliferative effects. By reducing CIC populations, we hypothesize lunasin alters the ability of melanoma tumor cells to establish palpable tumors in vivo. By selectively reducing the population of melanoma cells with the ability to form solid tumors and metastasize, lunasin has a potential therapeutic application. 


\section{METHODS}

\section{$\underline{\text { Lunasin Isolation and Purification }}$}

Lunasin was isolated from "white flake," a product resulting from the flaking and defatting of soybeans via hexane extraction. The extraction and purification was scaled and performed by Kentucky BioProcessing (KBP) as previously described [6]. Briefly, lunasin was extracted from defatted soy flour and purified using a combination of QSepharose FF chromatography, ultrafiltration utilizing a 30 kDa membrane, and. reversephase chromatography. Sodium dodecyl sulfate polyacrylamide gel electrophoresis (SDS-PAGE) analysis indicate these lunasin preparations have $>99 \%$ purity.

\section{$\underline{\text { Cell Culture and Reagents }}$}

SKMEL-28 and A375 cell lines were obtained from American Type Culture Collection (ATCC, Rockville, MD, USA). Cell lines were grown in Dulbeccos Modified Eagles Medium (DMEM) and supplemented with 10\% fetal bovine serum (FBS), 100 $\mathrm{U} / \mathrm{mL}$ penicillin, and $100 \mu \mathrm{g} / \mathrm{mL}$ streptomycin. Cells were incubated at $37^{\circ} \mathrm{C}$ at $5 \% \mathrm{CO}_{2}$ and subcultivated every 72 hours. Vemurafenib was obtained from Selleck Chemicals (Houston, TX). DMEM media (Invitrogen) was reconstituted in 500mL ultrapure $\mathrm{H}_{2} \mathrm{O}$ and supplemented with $20 \% \mathrm{FBS}, 200 \mathrm{U} / \mathrm{mL}$ penicillin, and $200 \mu \mathrm{g} / \mathrm{mL}$ streptomycin for use in soft agar assays.

\section{$\underline{\text { Proliferation Assays }}$}

Manufacturer protocols were followed to determine effect of lunasin on melanoma cell proliferation (Promega Cell titer-96 Aqueous Reagent). Initial seeding 
densities were standardized at $7.5 \times 10^{3}$ cells $/ \mathrm{cm}^{2}$ in $100 \mu \mathrm{L}$ culture media. Briefly, cells were plated and incubated at $37^{\circ} \mathrm{C}, 5 \% \mathrm{CO}_{2}$ for 4 hours. Media were drained from each well and replaced with media containing varying concentrations of lunasin. Treatment media were replaced every 24 hours during the 72 hour treatment period. After 72 hours of treatment, wells were drained of expired media and refilled with fresh media. $20 \mu \mathrm{L}$ [3-(4,5-dimethylthiazol-2-yl)-5-(3-carboxymethoxyphenyl)-2-(4-sulfophenyl)-2Htetrazolium (MTS) reagent was added to each well and the plate was incubated for 2-3 hours. Absorbance was read at $490 \mathrm{~nm}$ on a plate reader (Biotek Instruments, Winooski, VT). Average absorbance of media containing no cells was subtracted from all absorbance values. Absorbance values were then normalized to control and expressed as percent control.

\section{$\underline{\text { Soft Agar Colony Forming Assay }}$}

In order to assess the ability of lunasin to suppress anchorage-independent growth of cancer cell lines, cells were suspended in soft agar. Solutions of $1 \%$ and $0.7 \% \mathrm{w} / \mathrm{v}$ Bacto Agar were mixed with equal volumes (1:1) of 2x DMEM media containing 20\% FBS and $2 \%$ Pen-Strep. $2 \mathrm{~mL}$ of $0.5 \%$ agar solution was used to coat the bottom of each well in a 6-well plate and allowed to solidify in a laminar flow hood. $1 \times 10^{3}$ cells were suspended in a $1 \mathrm{~mL}$ top layer containing $0.3 \%$ agar with and without lunasin present and placed on top of the bottom layer of agar. Plates were allowed to fully solidify and were placed in the incubator. Generally, colony formation occurred within 2-3 weeks. Colonies were stained with a $1 \mathrm{mg} / \mathrm{mL}$ iodonitrotetrazolium chloride (Sigma-Aldrich, St. Louis, MO ) solution and counted using a light microscope. Images from each well were analyzed using ImageJ software (National Institutes of Health, Bethesda, Maryland). 


\section{$\underline{\text { ALDEFLUOR Staining and Flow Cytometry }}$}

The ALDEFLUOR kit (Stem Cell Technologies, Vancouver, BC) was used to identify cells with high ALDH activity. Briefly, cells were suspended in assay buffer containing a fluorescent ALDH substrate and incubated for 30 min at $37{ }^{\circ} \mathrm{C}$. The ALDH substrate passively diffuses into live cells and is then converted by ALDH into a fluorescent product detectible by FL-1 (FITC) signal. A specific ALDH inhibitor, diethylaminobenzaldehyde (DEAB) served as a negative control and allowed gating of ALDH-positive cells. Becton, Dickinson, and Co. FACS Caliber (BD Biosciences San Jose, CA) was used for all flow cytometry experiments.

Annexin $\mathrm{V}$ binding assays were conducted using FITC conjugated antibodies (BD Bioscience) and propidium iodide to measure rates of apoptosis/cell death. Cells were harvested and resuspended in 1x binding buffer (0.1 M HEPES, pH 7.4; $1.4 \mathrm{M} \mathrm{NaCl} ; 25$

$\mathrm{mM} \mathrm{CaCl} 2$ ) at a concentration of $1 \times 10^{6}$ cells per $\mathrm{mL}$. Staining was conducted following manufacturer protocols. Briefly, $1 \times 10^{5}$ melanoma cells were incubated with $100 \mu \mathrm{M}$ lunasin for 24, 48, and 72 hours. Cells were suspended in $0.5 \mathrm{~mL}$ binding buffer and stained with $5 \mu \mathrm{L}$ PI, $5 \mu \mathrm{L}$ Annexin antibody, or both for 15 minutes at room temperature. Gates were set based on controls (unstained, PI only, Annexin only). $1 \times 10^{4}$ events were collected per run.

Cell cycle analysis was performed on synchronized melanoma cells; cells were serum starved for 72 hours and then released by addition of FBS during lunasin or vehicle treatment. $1 \times 10^{6}$ cells were harvested and resuspended in $200 \mu \mathrm{L}$ PBS. Cells were slowly added to $4 \mathrm{~mL}$ ice cold $70 \%$ ethanol for overnight fixation at $-20^{\circ} \mathrm{C}$. After fixation, cells were spun down at $300 \mathrm{~g}$ for 10 minutes and resuspended in $0.5 \mathrm{~mL}$ of PI 
master mix (40 $\mu \mathrm{g} / \mathrm{mL}$ PI, $100 \mu \mathrm{g} / \mathrm{mL}$ DNase in PBS) and incubated at $37^{\circ} \mathrm{C}$ for 30 minutes prior to flow anaylsis.

Fluorescence-assisted Cell Sorting

A MoFlo cell sorter (Beckman Coulter, Brea, CA) was used for all fluorescence assisted cell sorting (FACS). ALDH-positive and ALDH-negative fractions were isolated using FL1 signal and collected for subsequent in vitro and in vivo experiments. Sorted cells were confirmed to be positively stained for ALDH by fluorescent microscopy under blue laser (illumination at $488 \mathrm{~nm}$ ). Because a relatively large population of melanoma cells expressed at least some basal level of ALDH, only ALDH-positive cells with high FL1 intensity were collected. A representative histogram for FACS based on the ALDH biomarker is shown in Figure 3.

Formation of Multicellular Oncospheres

Stem-like cells isolated by FACS were cultured in low adherent T-25 flasks (Corning, Corning, NY) in DMEM culture media supplemented with $2 \%$ FBS at a density of $1 \times 10^{4}$ cells/mL. Cultures were grown for 28 days and treated every 48 hours during this time period with lunasin or vehicle in DMEM culture media. Oncospheres began to form around 14 days and continued to grow until they were harvested, dissociated, and counted. Visual counts of oncospheres were performed by light microscopy and analyzed using ImageJ software.

$\underline{\text { In vivo Xenograft Model }}$

In vivo experiments using 6-8 week old, male athymic nude mice (Jackson labs Stock\# 002019, Bar Harbor, Maine) illustrated the anticancer effects of lunasin in a xenograft model. Briefly, mice were injected subcutaneously (s.c.) with $2.5 \times 10^{6}$ A375 
cells reconstituted in $100 \mu \mathrm{L}$ phosphate buffered saline (PBS) on the right flank. Intraperitoneal (IP) injections of $30 \mathrm{mg} / \mathrm{kg}$ lunasin reconstituted in $50 \mathrm{mM}$ phosphate buffer, pH 7.4 (PB) were administered starting immediately after s.c. injection of tumor cells and repeated every 24 hours. Noticeable tumor formation was observed approximately 14 days post-injection and measured every other day thereafter. Experimental endpoint was set at tumor volumes exceeding $20 \mathrm{~mm}$ in diameter or ulceration of tumor tissues. At endpoint, mice were sacrificed and organs were resected for slide preparations.

For MMIC studies, $1 \times 10^{4} \mathrm{ALDH}^{+}$cells were reconstituted in Hank's Balanced Salt Solution (HBSS) +calcium +magnesium (Invitrogen) with an equal volume of Matrigel (BD Biosciences) and injected on the dorsal side of the mice at a total volume of $100 \mu \mathrm{L}$. Palpable tumor formation was observed at approximately 16 days post-injection and measured every other day as described above. Again, organs were resected and blood was drawn via cardiac puncture upon sacrifice for future processing.

\section{$\underline{\text { SDS-PAGE and Immunoblot }}$}

Cultured cells were harvested by using enzyme free dissociation buffer to minimize protein degradation, spun down, and washed in ice-cold PBS. After pelleting, cells were resuspended in appropriate amounts of RIPA buffer $(250 \mathrm{mM}$ Tris- $\mathrm{HCl}, \mathrm{pH}$ 7.5, 5 mM EDTA, $750 \mathrm{mM} \mathrm{NaCl}$, 0.5\% Lauryl sulfate, 2.5\% Deoxycholic acid, 5\% Igepal CA-630, Protease inhibitor cocktail containing 4-(2-aminoethyl) benzenesulfonyl fluoride (AEBSF), pepstatin A, bestatin, leupeptin, aprotinin and trans-epoxysuccinyl-Lleucyl-amido(4-guanidino)-butane (E-64) (Sigma-Aldrich). Protein concentrations of cell lysates were determined by a bicinchoninic acid (BCA) assay (Thermo Fisher Scientific, 
Waltham, MA). $20 \mu \mathrm{g}$ of protein were loaded into $10 \%$ polyacrilamide gels (BioRad, Hercules, CA) and run at 100 volts for 1 hour. The protein was then transferred to a polyvinylidene difluoride (PVDF) membrane (BioRad) at 350 milliamps for 1 hour. The PVDF membrane was blocked with $5 \%$ bovine serum albumin (BSA) or non-fat dry milk for 1 hour. After several washing steps, primary antibodies were incubated with membrane at $4^{\circ} \mathrm{C}$ overnight. FAK (Cell Signaling, Danvers, Massachusetts), AKT (Cell Signaling), phospho-FAK (Cell Signaling), and phospho-AKT (Cell Signaling) monoclonal antibodies were diluted in Tris Buffered Saline with 0.1\% Tween (TTBS) at 1:1000 - 1:2000 v/v. After three washes, secondary antibodies at 1:10,000 dilutions (Cell Signaling) were incubated with the membrane for 1 hour at room temp.

Electrochemiluminescent (ECL) substrate/enhancer solutions (Thermo Fisher) were allowed to activate horseradish peroxidase (HRP) signal on membrane for 2-3 minutes; Chemiluminescence was developed on x-ray film and/or detected using a ChemiDoc station (BioRad).

$\underline{\text { Non-steroidal anti-inflammatory drug (NSAID) Toxicological Panel and Complete Blood }}$ Count (CBC)

Whole blood was drawn from athymic nude mice by cardiac puncture immediately following $\mathrm{CO}_{2}$ asphyxiation and collected in serum separator tubes (BD Biosciences) or EDTA coated collection tubes (BD Biosciences). $25 \mu \mathrm{L}$ of whole blood were collected in EDTA coated tubes and send to the RRC facility at the University of Louisville for $\mathrm{CBC}$ analysis. After 1 hour post-collection, whole blood collected in serum separator tubes were centrifuged for 10 minutes at 10,000 g. $250 \mu \mathrm{L}$ of serum was removed from each sample, collected in a $1.5 \mathrm{~mL}$ eppendorf tube, and send to the RRC 
facility for NSAID toxicological analysis. Liver damage was assessed by levels of alanine aminotransferase (ALT), aspartate aminotransferase (AST), and alkaline phosphatase (ALKP). Kidney damage was assessed by level of blood urea nitrogen (BUN) and creatinine (CREA).

$\underline{\text { Statistical Analysis }}$

All data were analyzed in three independent experiments. In vitro results were analyzed using GraphPad Prism (v 5.0) software and shown as mean \pm standard deviation (SD). Comparison of results from treated versus control cells was done using unpaired Student's $t$ test. A p-value of less than 0.05 was considered statistically significant. In vivo experiments were statistically analyzed using GraphPad Prism ANOVA analysis tool $(\mathrm{p}<0.05)$, and shown as mean \pm standard error $(\mathrm{SEM})$. Individual data points were compared by unpaired Student's $t$ test $(\mathrm{p}<0.05)$ to determine significance. Interactions between lunasin and vemurafenib were determined to be antagonistic $(<1)$, additive (1), or synergistic (>1) by calculating the Drewinko Index. All samples were normalized to appropriate controls and applied to the formula DI $=\frac{\left(S F^{1}\right)\left(S F^{2}\right)}{S F^{3}}$ in which $\mathrm{SF}^{1}$ is equal to the surviving fraction of $\operatorname{drug}^{1}$, effect ${ }^{2}$ is equal to the surviving fraction of $\mathrm{drug}^{2}$, and effect ${ }^{3}$ is equal to the surviving fraction of the combination of $\operatorname{drug}^{1}$ and $\mathrm{drug}^{2}$. 


\section{RESULTS}

\section{$\underline{\text { Lunasin has modest antiproliferative effects on melanoma in adherent cell culture }}$}

Proliferation assays remain an effective and high throughput method for screening drug efficacy. We used a tetrazolium based proliferation assay to determine if lunasin displayed a significant antiproliferative effect on melanoma cell lines. MTS results (Figure 4) indicate that lunasin marginally inhibits proliferation in adherent conditions and has an additive interaction with the B-Raf inhibitor vemurafenib as calculated by Drewinko Index assessment $(\mathrm{DI}=1)$. We replicated these experiments with cells isolated based on high expression of the ALDH biomarker using FACS. ALDH positive cells showed no significant difference from the parental cell lines in terms of sensitivity to lunasin using this culture method. Figure 4 illustrates that lunasin interacted additively with vemurafenib in both parental and $\mathrm{ALDH}^{+}$cells as assessed by DI. $\underline{\text { Lunasin reduced anchorage-independent growth of melanoma cells in soft agar }}$

Soft agar assays represent a robust system for screening cancer cells for drug sensitivity that is thought to be more representative of potential in vivo effects. We observed a heightened sensitivity of melanoma cells to lunasin when plated in soft agar versus adherent culture conditions (Figure 5). This is consistent with previous studies in our lab in which lunasin-insensitive NSCLC lines displayed lunasin sensitivity in a nonadherent format (McConnell and Davis, unpublished data). Lunasin showed a significant antiproliferative effect on A375 melanoma cells plated in soft agar. $30 \mu \mathrm{M}$ lunasin reduced colony formation by approximately $25 \%$, while $100 \mu \mathrm{M}$ lunasin inhibited colony 
formation by $38 \%$ (Figure 5A). Along with decreased colony counts, a noticeable reduction in the size and change in phenotype accompanies lunasin treatment (Figure 5D) versus vehicle treated A375 cells (Figure 5E). Cells treated with lunasin formed colonies that tended to be less dense and displayed a somewhat dissociated phenotype. Furthermore, we found that lunasin interacts additively with the specific B-Raf inhibitor vemurafenib. A combination of $100 \mu \mathrm{M}$ lunasin plus 300, 700, and $1000 \mathrm{nM}$ vemurafenib yielded a significant decrease in colony formation, illustrating the potential application of lunasin as an adjuvant therapy in melanoma patients.

Lunasin alone shows an antiproliferative effect on the SKMEL-28 melanoma cell line (Figure 5B). Concentrations of $30 \mu \mathrm{M}$ and $100 \mu \mathrm{M}$ reduced colony formation of SKMEL-28 melanoma cells by $14 \%$ and $20 \%$, respectively (Figure 5B). The additive effect of lunasin was again measured with vemurafenib co-treatment; however, a statistically significant additive effect was not obtained at $700 \mathrm{nM}$ vemurafenib. Anchorage independent growth is a hallmark of cancer; these data illustrate the utility of chemotherapeutics in disrupting proliferation of cancer cells in non-adherent conditions. From this, we concluded that concurrent treatment of lunasin and the B-Raf inhibitor vemurafenib could be a legitimate therapeutic strategy in malignant melanomas with the V600E mutation.

Lunasin reduces the melanoma stem cell population in vitro

We conducted initial experiments in which A375 and SKMEL-28cells were treated with $1 \mu \mathrm{M}$ vemurafenib, $100 \mu \mathrm{M}$ lunasin, and a combination of both agents. Melanoma stem cell markers (e.g. ALDH) in the cell population were analyzed by flow cytometry. ALDH staining has been recognized as a technique to distinguish and isolate 
melanoma stem cells from bulk tumor populations. Our results indicated that both vemurafenib and lunasin are able to dramatically reduce the population of cells expressing measureable levels of ALDH (Figure 6). This reduction in ALDH expression is time dependent. An overall reduction in ALDH-positive cells was seen with lunasin treatment, vemurafenib treatment, and in combination treatment groups.

Lunasin alone had a significant effect on ALDH expression in melanoma cells versus vehicle treatment (Figure 8). ALDH positive populations were reduced by nearly $50 \%$ in lunasin treated SKMEL-28 cells at 24 hours (Figure 8B). This effect was seen at later time points, albeit, it was not significantly different from controls. In A375 cells, ALDH positive populations were reduced by lunasin treatments; ALDH expressing cell populations were reduced $56 \%, 35 \%, 18 \%$, and $22 \%$ for $24,48,72$, and 96 hour time points, respectively (Figure 8A). By effectively reducing the tumor initiating cells in culture, lunasin may inhibit primary tumor formation or alter metastatic growth by inducing terminal differentiation of cancer stem cells or by reducing CIC pools available to invade distant tissues.

\section{Cell cycling and apoptotic effects on melanoma}

Trypan blue exclusion tests were performed in concurrence with annexin binding assays to measure apoptotic rates within melanoma cell populations. Initial experiments suggest that lunasin has little effect on cell viability; however, potentiates the apoptotic effects of vemurafenib in combination treatments (Figure 10). At the later time points, it was clear that a number of cells in both A375 and SKMEL-28 treated samples were dead or dying; however, these observations were apparent in both control and lunasin treated samples. Results from later annexin binding assays did not show a definitive increase in 
early or late apoptotic populations within either cell line at 24,48 , or 72 hours in response to $100 \mu \mathrm{M}$ lunasin (Figure 11). Apoptotic and necrotic profiles for each treatment and time point were generated, but no significant difference was seen in either cell line; although, a clear trend in increasing early and late apoptotic cells was observed with lunasin treatment. We therefore concluded that lunasin does not induce apoptosis or cause a necrotic response in the parental melanoma cell lines; however, we expect to isolate CICs based on the ALDH biomarker and determine if lunasin induces a selective apoptosis response in this subset of cells.

Cell cycle analysis was performed using propidium iodide (PI) staining of DNA (Figure 9). Briefly, cells were permeablized and fixed in $70 \%$ ethanol over night and resuspending in a PI master mix (PI $40 \mu \mathrm{g} / \mathrm{mL}$, RNase $100 \mu \mathrm{g} / \mathrm{mL}$ in PBS). Flow analysis commenced after a 30 minute incubation. Interestingly, lunasin had little effect on cell cycling of either melanoma cell line before the 72 hour time point. However, at 72 hours, a decrease of cells in S-phase was seen. These data may suggest lunasin has a delayed effect on cellular proliferation, and causes accumulation of cells in G0/G1 and G2 phases of the cell cycle. Treatment with vemurafenib caused a decrease in S-phase throughout the time course, and an accumulation of cells in G0/G1 can be seen in both cell lines. Combination treatment curves were similar to treatment with the B-Raf inhibitor, however, S-phase cycling was further reduced, and frequency of sub-G1/superG2 cells was modestly increased.

$\underline{\text { Lunasin reduced phosphorylation of Akt and Fak in melanoma cells }}$

Since lunasin was effective at inhibiting the growth of melanoma cells as colonies in soft agar, we studied whether it affects the signaling pathways associated with cell 
growth and survival. FAK and AKT are downstream mediators of integrin signaling. Figure 12 illustrates that total FAK $(125 \mathrm{kDa})$ remains unchanged with lunasin treatment; however, tyrosine phosphorylation (Y397) is significantly impaired. We next examined the serine phosphorylation (Ser473) of Akt (60 kDa), a downstream signal molecule of FAK. As expected, the phosphorylation of Akt was observed in untreated cells and inhibited by treatment with lunasin. These results confirm that downstream mediators of integrin signaling are severely affected by lunasin. By effectively reducing active forms of Akt and Fak, signal transduction is interrupted, which may stimulate antiproliferative and antisurvival cell signaling. Inhibiting these pathways may sensitize CICs with superior survival signaling and chemoresistance to traditional or targeted therapies (e.g. vemurafenib).

$\underline{\text { In vitro effects of lunasin were potentiated in melanoma stem cells }}$

In order to determine whether or not lunasin has a selective apoptotic or antiproliferative effect on cancer stem cells, in vitro assays measuring proliferation and anchorage-dependent growth were performed, and the results from the ALDH-positive populations were compared to the parental lines. Overall, lunasin had an increased effect in the $\mathrm{ALDH}^{+}$sorted cells. $100 \mu \mathrm{M}$ lunasin reduced colony forming ability in soft agar by approximately $40 \%$ and $75 \%$ in A375 and SKMEL-28 cell lines, respectively (Figure 14A). Interestingly, a reduction in colony size accompanied lunasin treatment in both cell lines versus vehicle treatment (Figure 14B-E)

CICs have been reported to have enhanced ability to form oncospheres in low adherent conditions. We assessed the ability of lunasin to disrupt formation of oncospheres derived from sorted samples based on the ALDH biomarker. $100 \mu \mathrm{M}$ 
lunasin almost completely inhibited spheroid formation in the A375 cell line versus control (Figure 13B and Figure 13C), while reducing spheroid counts and size in SKMEL-28 cells (Figure 13A). When spheres were dissociated and counted, viability did not significantly change due to lunasin treatment; however, slightly reduced cell counts as determined by trypan blue exclusion assays were observed (data not shown). Furthermore, lunasin inhibited foci formation when A375 CICs were dissociated and replated at low density in adherent conditions (Figure 13D and Figure 13E). ALDH positive cells quickly grew in tightly packed clusters of cells and formed foci within a matter of days. Lunasin restores growth of these cells as a monolayer and inhibits foci formation in adherent culture. These data suggest lunasin may convert the more tumorigenic ALDH expressing cells to the less aggressive phenotype of a terminally differentiated bulk tumor cell. More research into possible mechanisms for this effect is warranted as little is known about the movement of melanoma cells in and out of the stem cell compartment. Furthermore, a definitive link between cancer stem cells and integrin signaling has yet to be established in the roles of CSC differentiation, metastasis, and overall patient outcome.

Lunasin had significant antimelanoma effects in vivo:

Our results indicate lunasin substantially inhibits tumor formation and growth in an athymic nude mouse xenograft model. $30 \mathrm{mg} / \mathrm{kg}$ injections of lunasin reduced tumor volume by $35 \%$ and 55\% with intravenous (Figure 15) and intraperitoneal (Figure 16) injections, respectively. IV injections were administered every other day; IP every day. Tumor mass was also significantly decreased by lunasin treatments. Upon necroscopy, whole tumors were resected and a wet tumor weigh was measured. IP and IV lunasin 
treatments resulted in a $46 \%$ and $34 \%$ decrease in wet tumor weights upon endpoint of the experiment. These data delineate lunasin's bioavailability and anticancer effects in an in vivo model.

Non-steroidal Anti-inflammatory Drug (NSAID) toxicological panels showed lunasin treatments did not alter circulating plasma levels of liver enzymes ALKP, ALT, or AST. These data suggest lunasin does not induce a toxicological response in mice and is safe for future therapeutic applications. Furthermore, renal function was not impaired as measured by BUN and CREA. Complete blood count (CBC) analysis revealed lunasin does not significantly alter levels of leukocytes, erythrocytes, or thrombocytes compared to control.

\section{Lunasin selectively inhibits MSC proliferation in vivo}

Male athymic nude mice (6-8 weeks old) were transplanted with $1 \times 10^{4}$ cells that had previously been sorted using the ALDEFLUOR staining kit in an equal volume of HBSS (with calcium and magnesium) and Matrigel. Tumor formation was established at 16 days after injection and measured every other day thereafter. Control vehicle and 30 $\mathrm{mg} / \mathrm{kg}$ lunasin were injected IP every 24 hours for the duration of the experiment. Our results demonstrate the selective effect of lunasin on melanoma stem cells expressing the ALDH biomarker. These cells are generally accepted to have enhanced tumorigenic capacity versus non-sorted bulk tumor cells. Compared to our previous study in which we injected $2.5 \times 10^{6}$ bulk A375 cells, MSCs displayed superior tumor forming ability.

MMICs established palpable tumors in a similar amount of time compared to parental tumor cells, however, this experiment utilized Matrigel in order to keep MMICs localized to subcutaneous tumor growth. Matrigel contains growth factors which may 
boost cell proliferation; therefore, we concede that our MMIC and parental models are not comparable in terms of tumor growth rates. Lunasin did not decrease the number of tumors formed, but reduced tumor burden by $74 \%$, a nearly $50 \%$ increased effect versus parental A375 cells. Onset of tumor formation was delayed in lunasin treated mice; tumors also displayed linear growth versus the exponential growth seen in control mice. Wet tumor weights for lunasin treated mice were reduced by $66 \%$, thus illustrating the potential for lunasin to specifically target and inhibit growth of tumors derived from CICs. 


\section{DISCUSSION}

Lunasin has previously been shown to have chemotherapeutic effects in a number of cancer models $[3,23,25,83-85]$. To our knowledge, this is the first study identifying the anticancer effects of lunasin in a melanoma model. Therapies for treating patients with malignant melanoma remain largely ineffective, despite novel targeted therapies that show clinical improvements over traditional alkylating agents. Here we show that lunasin has potential clinical utility as both an adjuvant therapy as well as a standalone chemotherapeutic against malignant metastatic melanoma. Our data suggest that lunasin interacts with subsets of integrin subunits and interrupts internal signaling cascades induced by integrin activity.

Although HAT inhibition is generally regarded as the prime mechanism for lunasin's chemotherapeutic and chemopreventive attributes, we suggest the interactions between the RGD-peptide and integrin dimers found on the cell surface to be essential mechanisms in the in vitro and in vivo effects found in this study. Utilizing proximity ligation assays, we have shown that lunasin interacts with specific integrins (Ianaba and Davis, unpublished data), evidence supported by recent studies on integrin mediated endocytosis [27].

We do not postulate that the described effects are due to the epigenetic effects stimulated by lunasin treatment; though, we have found that lunasin does indeed affect patterns of histone acetylation in melanoma cells in vitro (data not shown). Because integrins are explicitly involved in cell adhesion and division, we concluded that 
reductions in clonogenic capacity in soft agar and formation of multicellular oncospheres in low adherent culture are attributed to the disruption of adhesive signaling mediated by integrins. We agree that HAT inhibition does have global cellular effects; however, we believe that lunasin binding of integrins through its RGD domain is responsible for lunasin's anticancer activity in our melanoma models. However, in vivo effects may stem from a variety of cellular effects induced by lunasin including integrin antagonism, epigenetic modifications, and immunomodulatory functions.

Integrin signaling can regulate the stem cell processes of self-renewal, differentiation, and proliferation [86]. We have shown that lunasin treatment altered these processes and diminished intracellular interactions with Akt and Fak in vitro and resulted in decreased tumor burden in vivo. Though lunasin decreased tumor burden in mice injected with parental A375 melanoma cells, these effects were exacerbated in MMIC populations in our xenograft models. Furthermore, we confirmed that lunasin depleted the stem cell pool by reducing ALDH signal in established melanoma cell lines. These effects may be associated with the ability of lunasin to induce terminal differentiation of CICs or by altering downstream mediators of integrin signaling. The enhanced effects seen in MMIC populations suggests that cancer stem cells may rely on integrin signaling for proliferation and differentiation, more so than bulk tumor populations. These finding are consistent with recent studies that suggest FAK as well as $\beta 1$ integrin subunits regulate stem cell pools in breast cancer [87].

Fak normally functions as a scaffolding protein to mediate signal transduction, however, Fak also serves as a non-receptor tyrosine kinase mediating signal transduction from external stimuli. Several studies correlate Fak overexpression or amplification with 
advanced disease resulting in poor prognosis $[88,89]$, consequently, targeting of FAK may provide a novel therapeutic strategy for inhibiting metastatic disease progression. FAK has been shown to arbitrate stem cell maintenance and differentiation in cancer models $[50,51]$. FAK association and activation of PI3K leads to increased production of phospholipids, which can in turn activate Akt kinase [90, 91]. Again, these finding are consistent with the results in our melanoma model as lunasin decreased phosphorylation of Akt. Therefore, integrin signaling through FAK may play an essential role in melanomagenesis or disease progression and metastasis; a pathway targeted by the lunasin peptide.

Crosstalk between PI3K/Akt and NOTCH signaling pathways in melanoma has been well documented $[92,93]$. NOTCH signaling has been implicated in stem cell processes such as self-renewal, differentiation, survival, and proliferation [94, 95]. It is plausible that the decreased Akt phosphorylation seen in melanoma cells is mediated through NOTCH signaling. Further studies are necessary to clarify whether or not lunasin induces changes in the PI3K/Akt pathway through NOTCH family receptors.

Another aspect of melanoma development is the theory of direct phenotype switching $[96,97]$. To summarize, three distinct compartments exist in cancers; a highly proliferative cell with low invasive capability, a differentiated phenotype derived from daughter cells of divided stem-like cells, and an invasive, stem-like, quiescent phenotype that regenerates stem cell pools. Switching between these subsets may rely on certain genes such as microphthalmia-associated transcription factor (Mitf) and NOTCH. $\mathrm{NOTCH}$ activity is frequently elevated in melanomas; it also maintains melanoctye stem cell populations [98]. As discussed previously, NOTCH can mediate PI3K/Akt 
signaling; overexpression of AKT by NOTCH1 provides a key step in promoting an invasive phenotype [99]. It has been shown that NOTCH1 is able to hyperactivate PI3K/Akt signaling through NF-KB [93], a pathway previously revealed to be inhibited in human macrophages by lunasin treatment [2].

Mitf has been established as a differentiation marker in melanocytes; however, Mitf has also been reported to mediate proliferation, differentiation, and plasticity of melanoma cells [100]. Insightful studies have addressed that melanomas with a negative Mitf phenotype are generally quiescent, yet highly invasive [101]. Inversely, melanoma cells highly expressing MITF proliferate rapidly, but do not seem to metastasize. In support of these findings, inhibition of MITF increased expression of stem cell markers Nanog and Oct4 resulting in enhanced tumor growth in C57/B6 mice [102]. Again, culture conditions played a major role in expression of differentiation and stem markers [100, 103]. Hoek and Goding summarize: "If the combination favours the proliferative phenotype over the invasive, a tumour may grow rapidly, but for a given size, it will seed fewer metastases than a tumour whose cells are not subject to a proliferative phenotype bias." [97] This hypothesis highlights the potential of selectively targeting cancer stem cells instead of relying on drugs targeting rapidly dividing cell populations to increase the overall efficacy of treatment in metastatic melanomas.

Clearly, these signaling pathways are implicated in both physiological and cancer stem cell processes. Our results show an apparent decline in cancer stem cell pools that may be influenced by these pathways; however, the potentiated effect in ALDH positive MSCs cannot be fully explained until further research elucidates lunasin's effects on certain genes and gene products responsible for maintenance, proliferation, and 
differentiation of stem-like cancer cells. Our data hints that lunasin may alter stem pool maintenance and proliferation, and therefore, has clinical utility in cases of late stage melanoma in which traditional therapies have failed. Future studies in our lab will focus on exploring the alterations induced by lunasin on cancer stem cell populations in established melanoma lines. 


\section{SUMMARY AND CONCLUSIONS}

The soy-derived peptide lunasin has significant activity as a chemopreventive [7]; however, lunasin also serves as an anticancer agent in established cancer models [24, 83]. Lunasin treatment reduces the capacity of melanoma cells to form oncospheres in low adherent culture as well as inhibits clonal growth in soft agar. We believe these results stem from an interaction between lunasin and integrins on the ECM through its RGD domain, and results in decreased phosphorylation of intracellular signaling proteins such as Fak and Akt. In vivo studies show lunasin significantly decreased tumor growth in athymic nude mice injected subcutaneously with A375 melanoma cells. Tumor volume and weight were reduced by $55 \%$ and $46 \%$, respectively. These data illustrate the potential clinical utility of lunasin against malignant melanoma.

Furthermore, we present a unique study showing the enhanced effects of lunasin against stem-like melanoma cells which display superior tumor forming capability compared to bulk tumor cells. Using ALDH, a recognized MMIC biomarker [77], we isolated cells expressing distinctively higher levels of the enzyme and subjected them to further in vitro testing. We found that MMIC response to lunasin treatment was potentiated versus the parental cell lines both in vitro and in vivo. $30 \mathrm{mg} / \mathrm{kg}$ lunasin treatment reduced tumor burden in our melanoma xenograft model by approximately $75 \%$. Despite using appreciably fewer cells to initiate tumor formation, ALDH expressing cells formed palpable tumors within a comparable amount of time versus bulk tumor populations. 
The functional assays in this study illustrate the prospective use of lunasin as a chemotherapeutic against melanomas in which traditional therapy has failed. Additionally, we showed that extended lunasin treatment displayed no toxicological effects versus control in our animal model. However, we have only begun to elucidate mechanisms in which lunasin acts as an anticancer agent. While epigenetic effects undoubtedly play a major role in tumorigenesis, we feel that lunasin has several critical effects on integrin signaling and further, CIC maintenance and proliferation resulting in the augmented effects seen in MMICs.

It must be taken into consideration that several theories exist in which cells are able to move between stem and differentiated cell compartments; theories in which melanoma serves as a prime example. If this is the case, more research is warranted to determine if A) lunasin is inducing terminal differentiation of melanoma cells, B) confirm ALDH as a viable biomarkers for MMIC populations by utilizing alternative markers, and C) analyze the alterations in gene expression patterns induced by lunasin treatment to further advance our understanding of the peptides anticancer effects. 


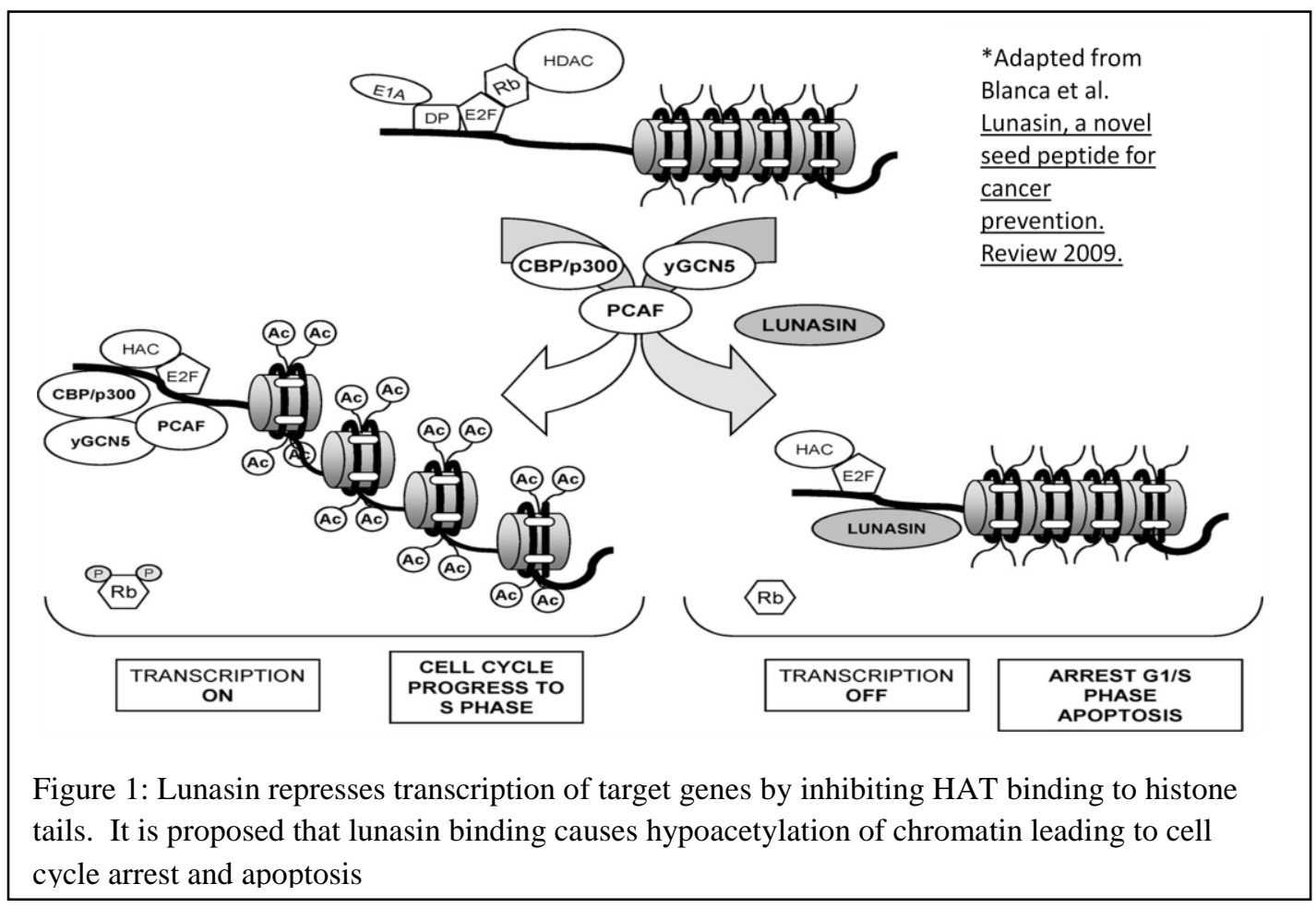




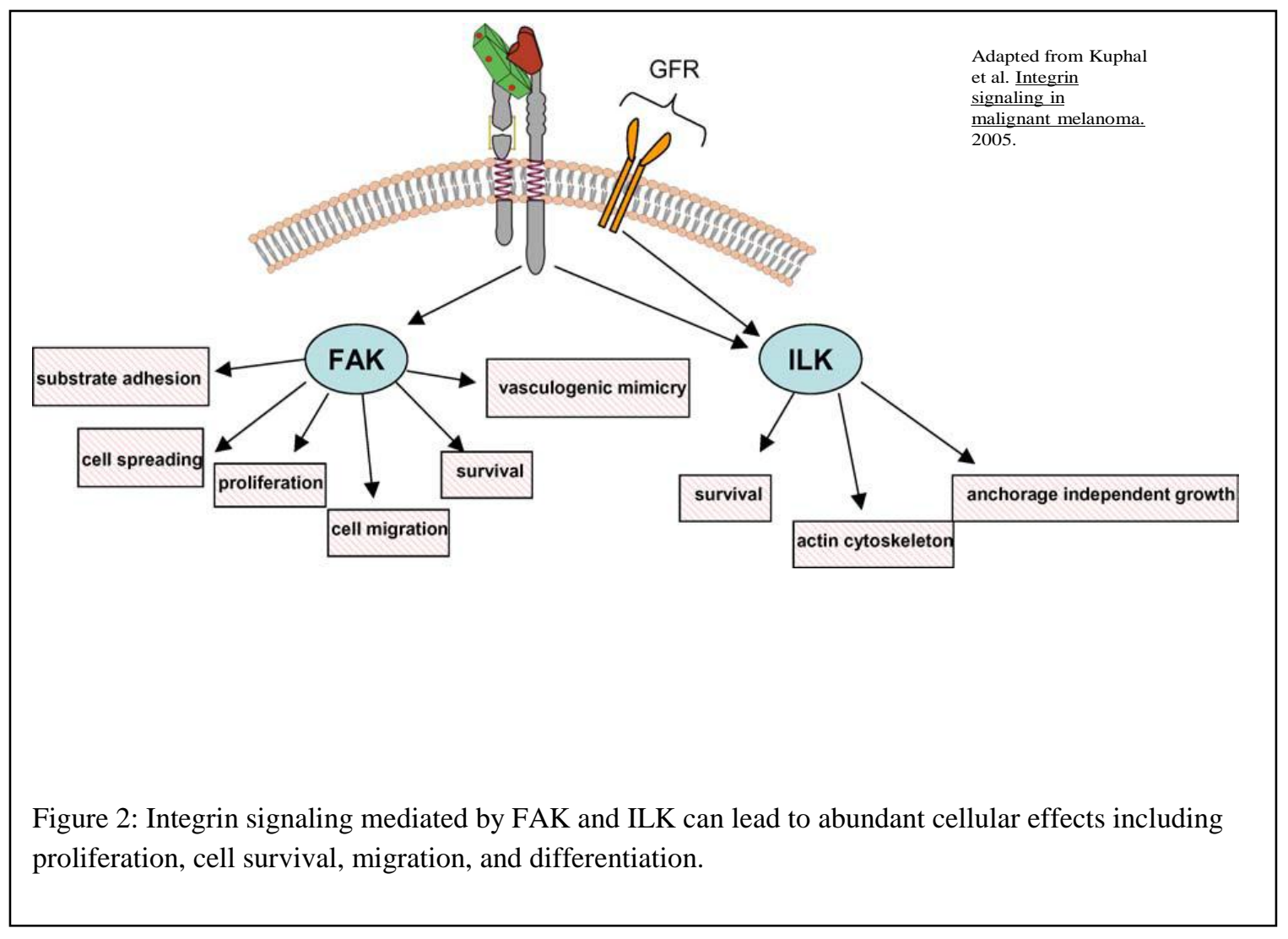




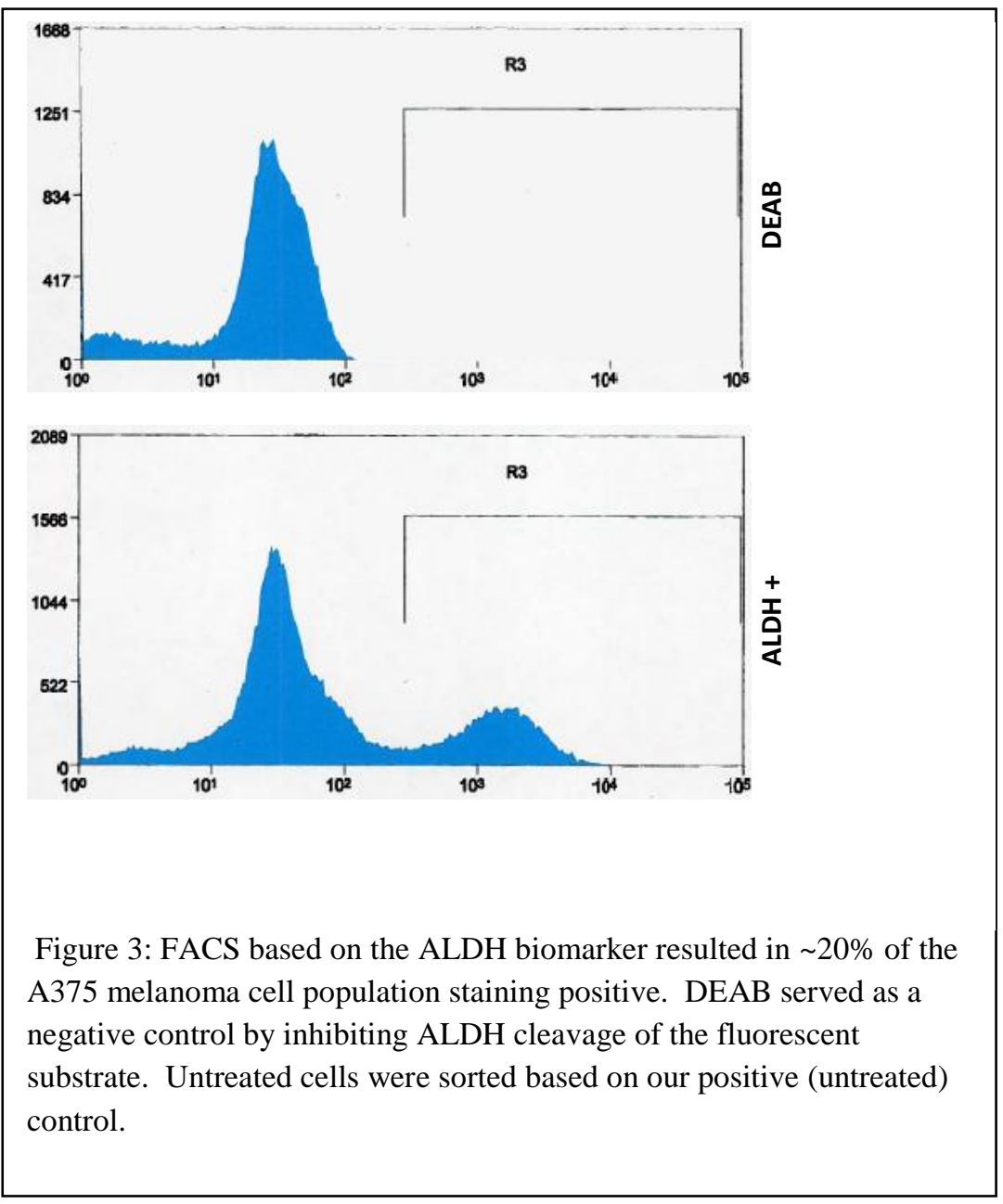



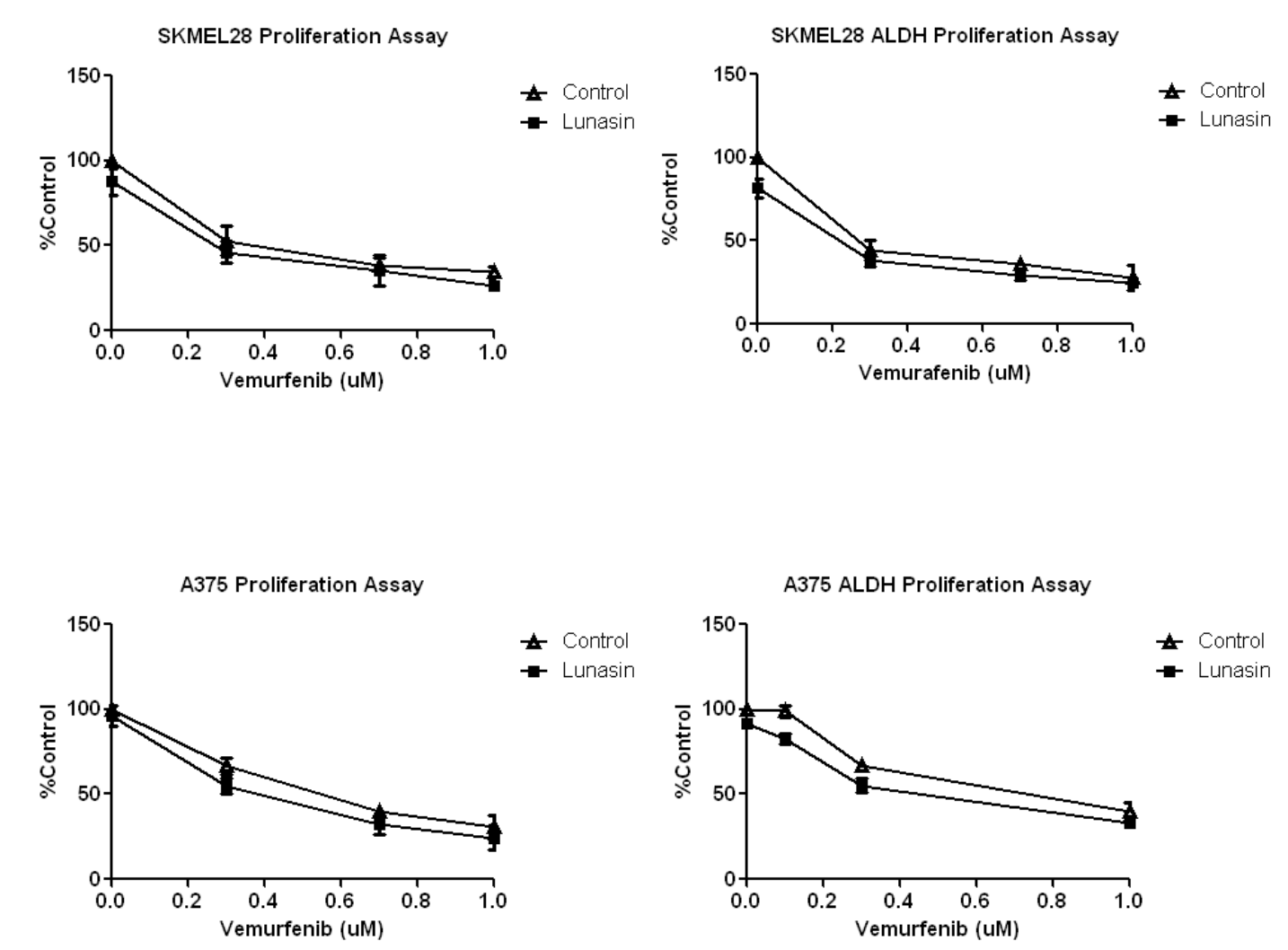

Figure 4: Tetrazolium-based proliferation assays (i.e. MTT) showed A375 and SKMEL-28 melanoma cell lines are relatively insensitive to lunasin $(100 \mu \mathrm{M})$ treatment in adherent conditions. ALDH-positive cells showed little sensitivity in this format as well, however, lunasin still interacted additively with the B-Raf inhibitor vemurafenib as calculated by Drewinko Index (DI). 


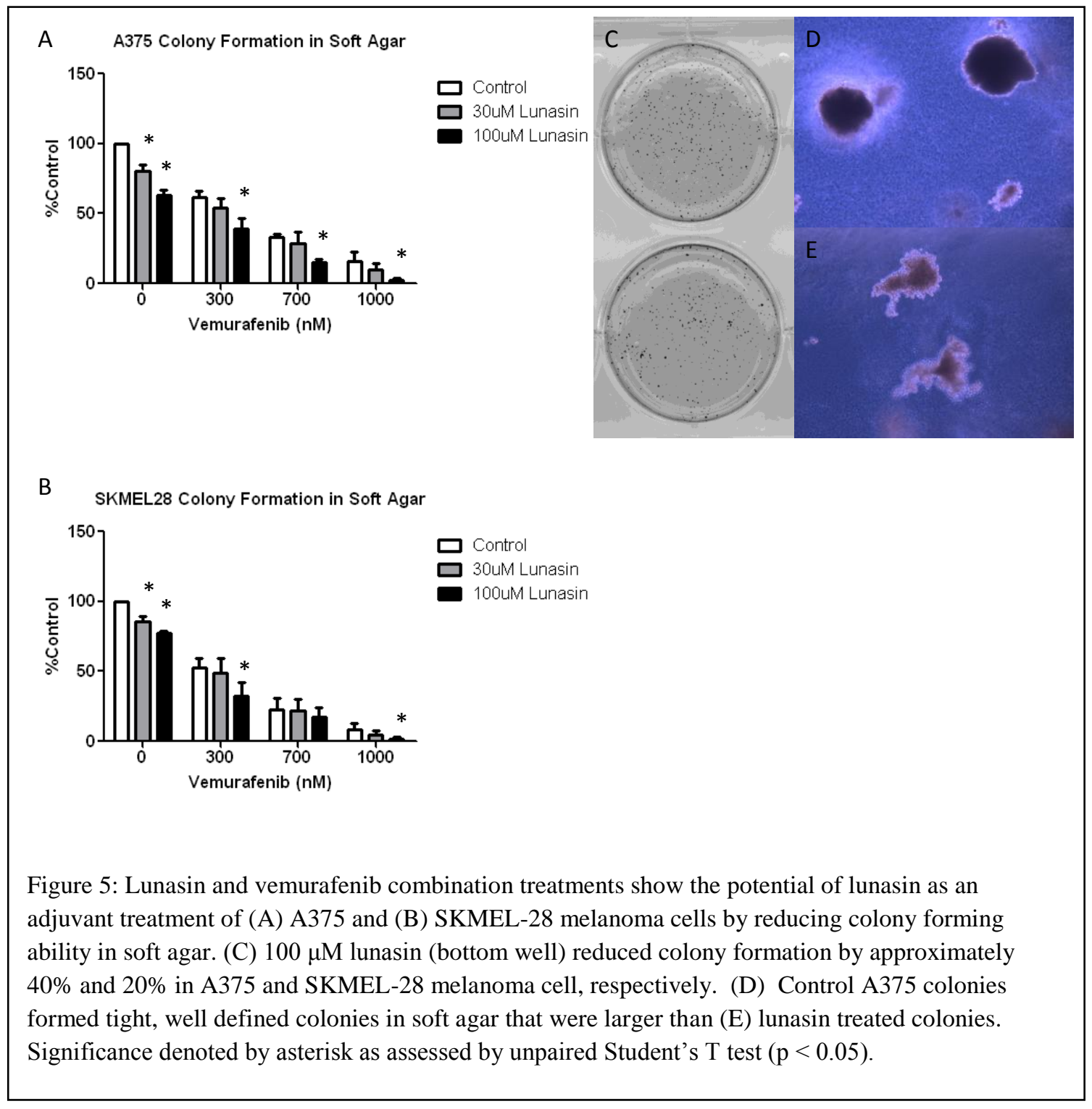




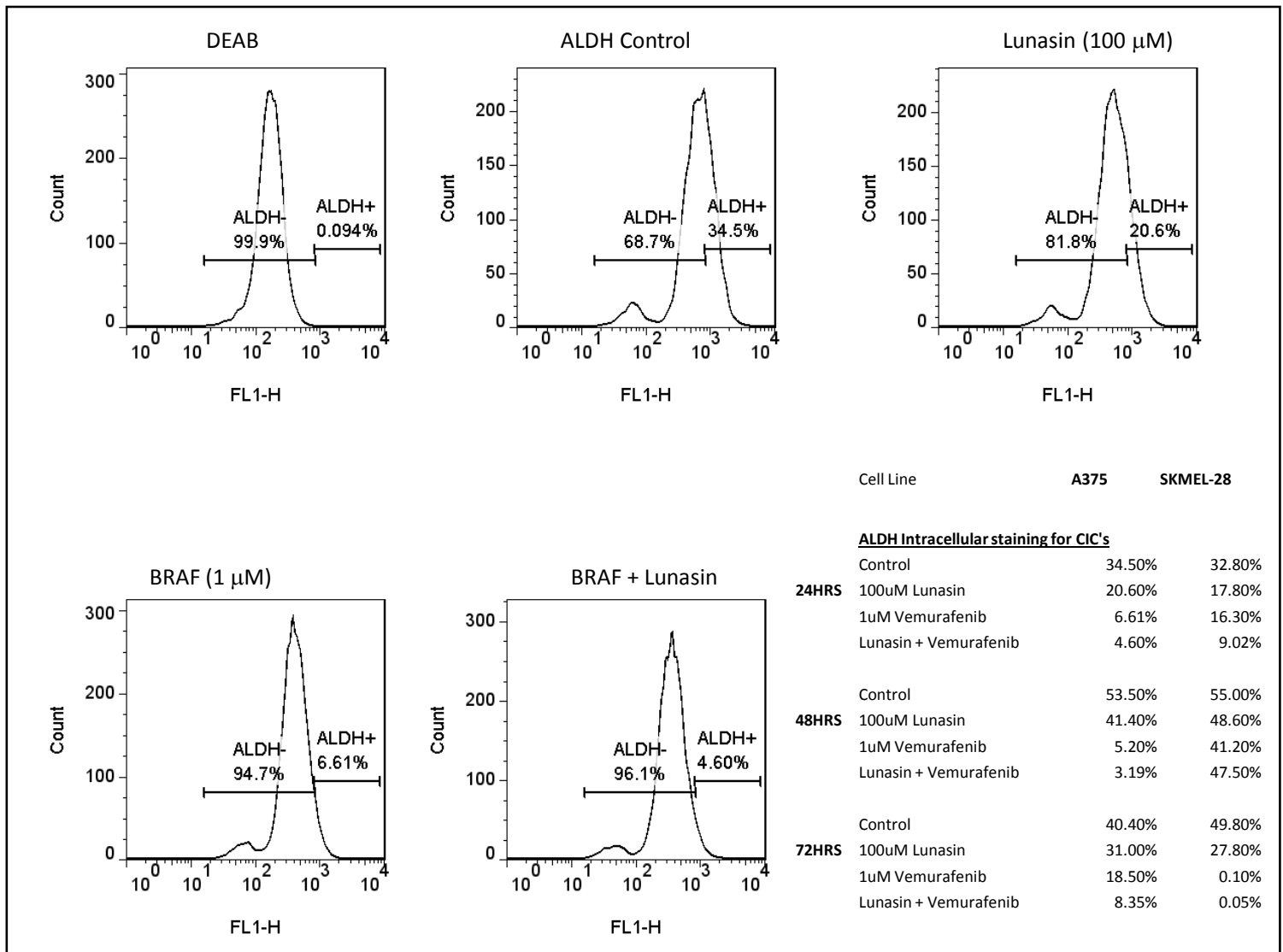

Figure 6: Lunasin and vemurafenib treatment decreased the number of $\mathrm{ALDH}^{\text {high }}$ cell populations in A375 and SKMEL-28 melanoma cells. Combination treatment further reduced ALDH expression in both cell lines, however, this effect was less pronounced at later time points. $(n=1)$ 

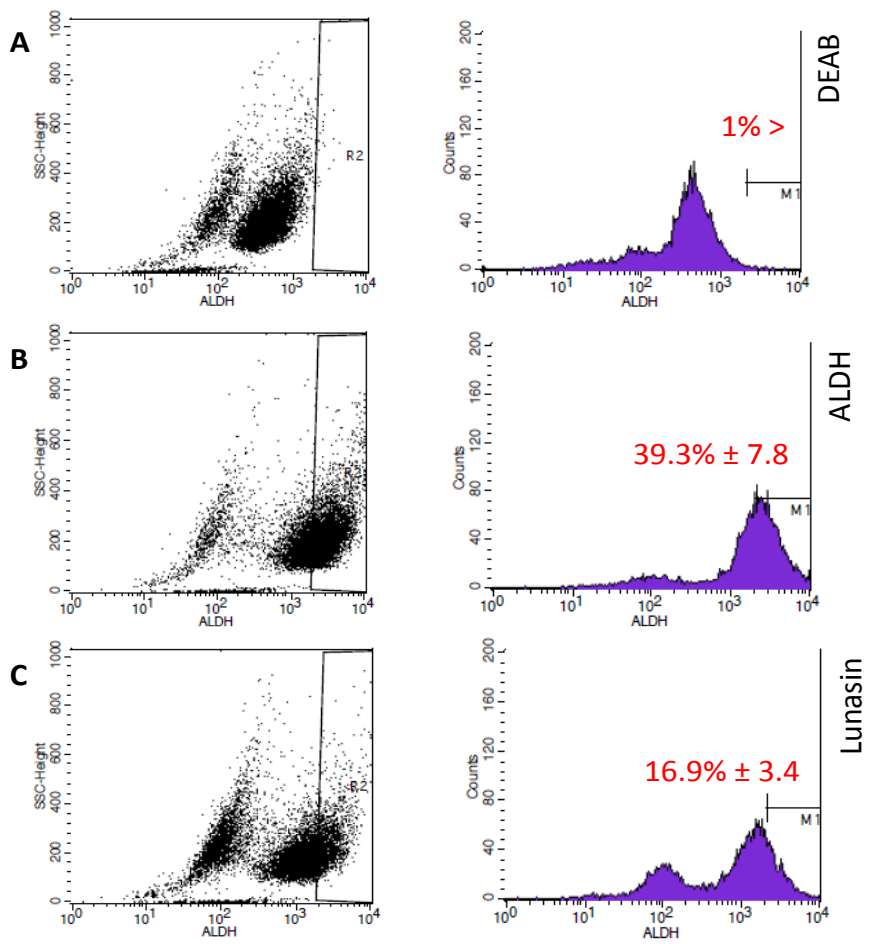

Figure 7: ALDH represents a unique biomarker to identify and isolate melanoma stem cells. Here we use the specific ALDH inhibitor DEAB as a negative control (A) to determine parameters for ALDH-positive (B) cells. We show that $100 \mu \mathrm{M}$ lunasin (C) treatments for 24 hours reduced ALDH expressing populations in melanoma cell lines, while concurrently 


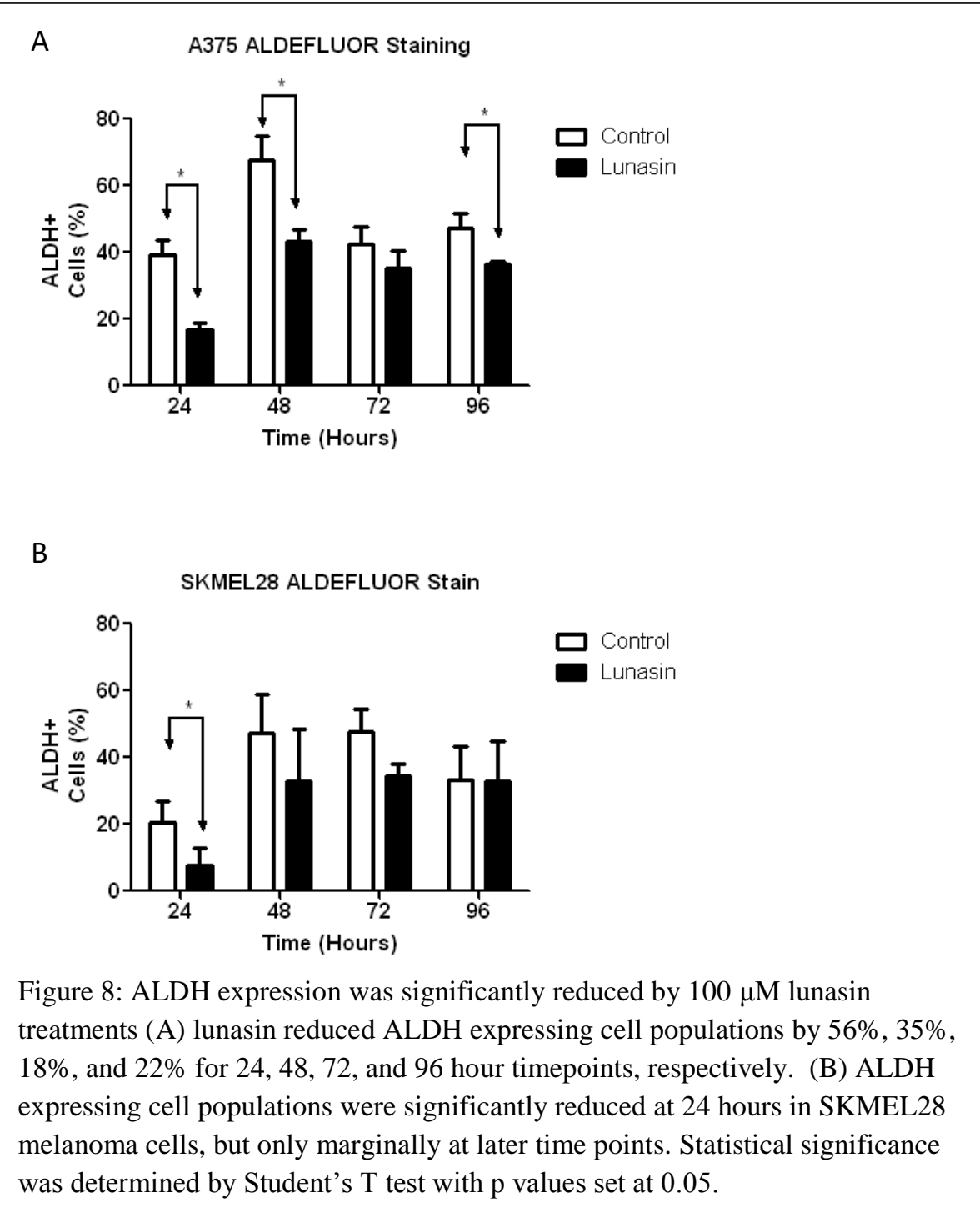




\begin{tabular}{|c|c|c|c|c|c|c|c|c|c|c|}
\hline & & & A375 & & & & \multicolumn{4}{|c|}{ SKMEL-28 } \\
\hline & G1 & $\mathrm{s}$ & G2 & Sub-G1 & Super-G2 & G1 & $\mathrm{s}$ & G2 & Sub-G1 & Super-G2 \\
\hline Control & 20.06 & 36.71 & 25.79 & 2.86 & 8.97 & 52.5 & 36.85 & 8.18 & 0 & 0 \\
\hline 100um Lunasin & 22.03 & 35.39 & 24.99 & 2.25 & 8.84 & 41.24 & 35.61 & 9.49 & 1.58 & 3.95 \\
\hline 1 uM Vemurafenib & 28.26 & 22.86 & 29.22 & 2.79 & 13.88 & 64.99 & 15.18 & 4.75 & 8.84 & 6.24 \\
\hline Lunasin + Vemurafenib & 25.43 & 21.04 & 29 & 3.21 & 17.23 & 44.83 & 15.6 & 39.44 & 8.52 & 24.83 \\
\hline Control & 40.8 & 32.6 & 29.6 & 1.31 & 3.19 & 53.7 & 26.2 & 8.1 & 0.74 & 0.73 \\
\hline 100um Lunasin & 38.5 & 32.8 & 20.1 & 2.16 & 3.09 & 51.9 & 25.6 & 11.9 & 1.56 & 0.36 \\
\hline 1 uM Vemurafenib & 77.4 & 14.2 & 3.6 & 2.22 & 0.04 & 72.7 & 15.7 & 2.8 & 4.79 & 1.27 \\
\hline Lunasin + Vemurafenib & 70.3 & 13.1 & 9.6 & 2.62 & 3.73 & 63.7 & 18.2 & 4.6 & 6.64 & 3.04 \\
\hline Control & 42.2 & 36.5 & 14.3 & 4.81 & 2.2 & 45 & 21.8 & 6.1 & 4.71 & 0.06 \\
\hline 100um Lunasin & 37.3 & 8.1 & 22.7 & 4.27 & 24.2 & 36.6 & 18.9 & 8.7 & 2.34 & 4.24 \\
\hline 1uM Vemurafenib & 38 & 6.6 & 20.8 & 9.99 & 22.23 & 69.2 & 7.4 & 0.5 & 13.73 & 0.03 \\
\hline Lunasin + Vemurafenib & 18.4 & 6.6 & 10.9 & 23.5 & 32.97 & 55.5 & 11.4 & 1 & 14.69 & 0.38 \\
\hline
\end{tabular}

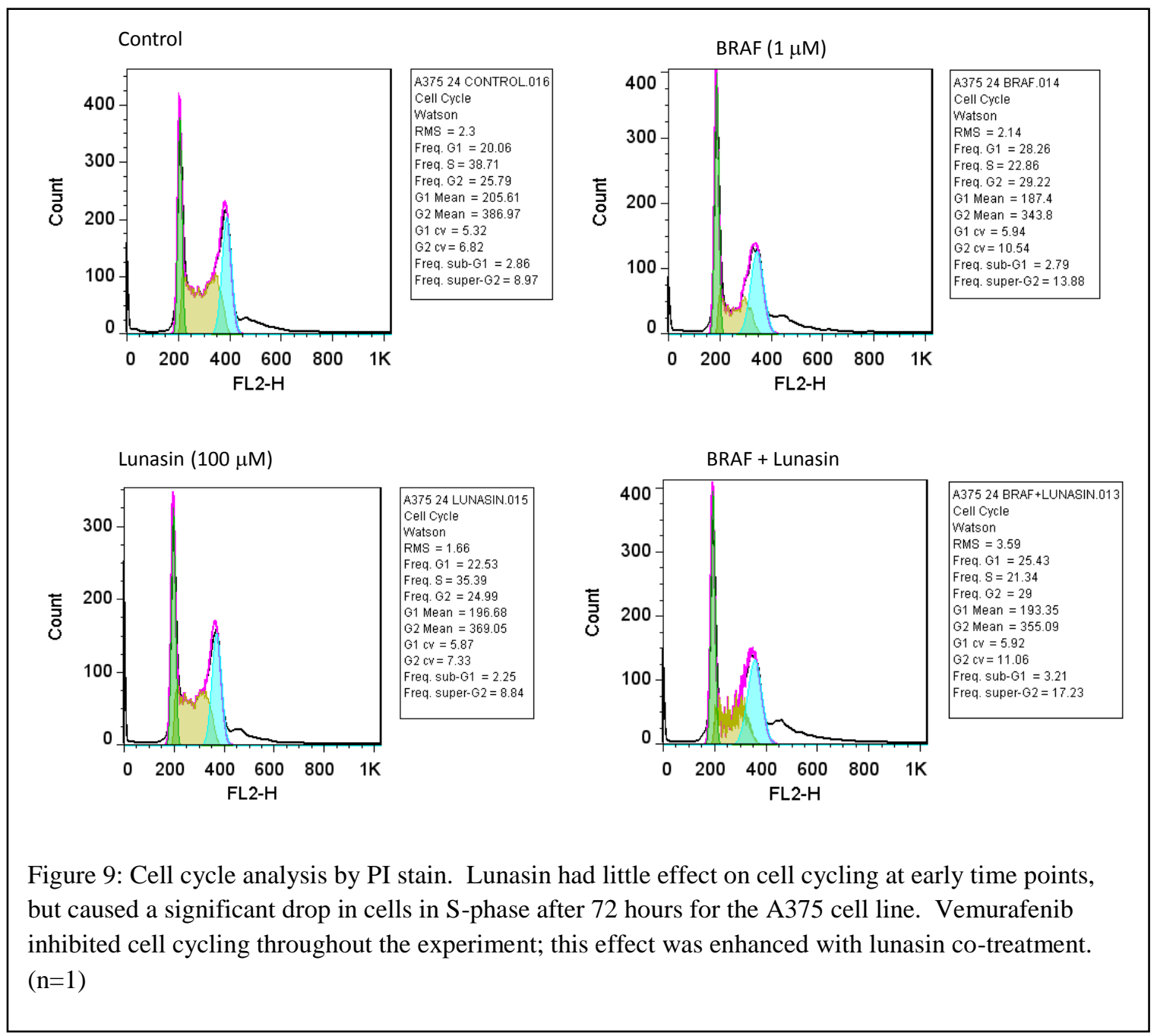



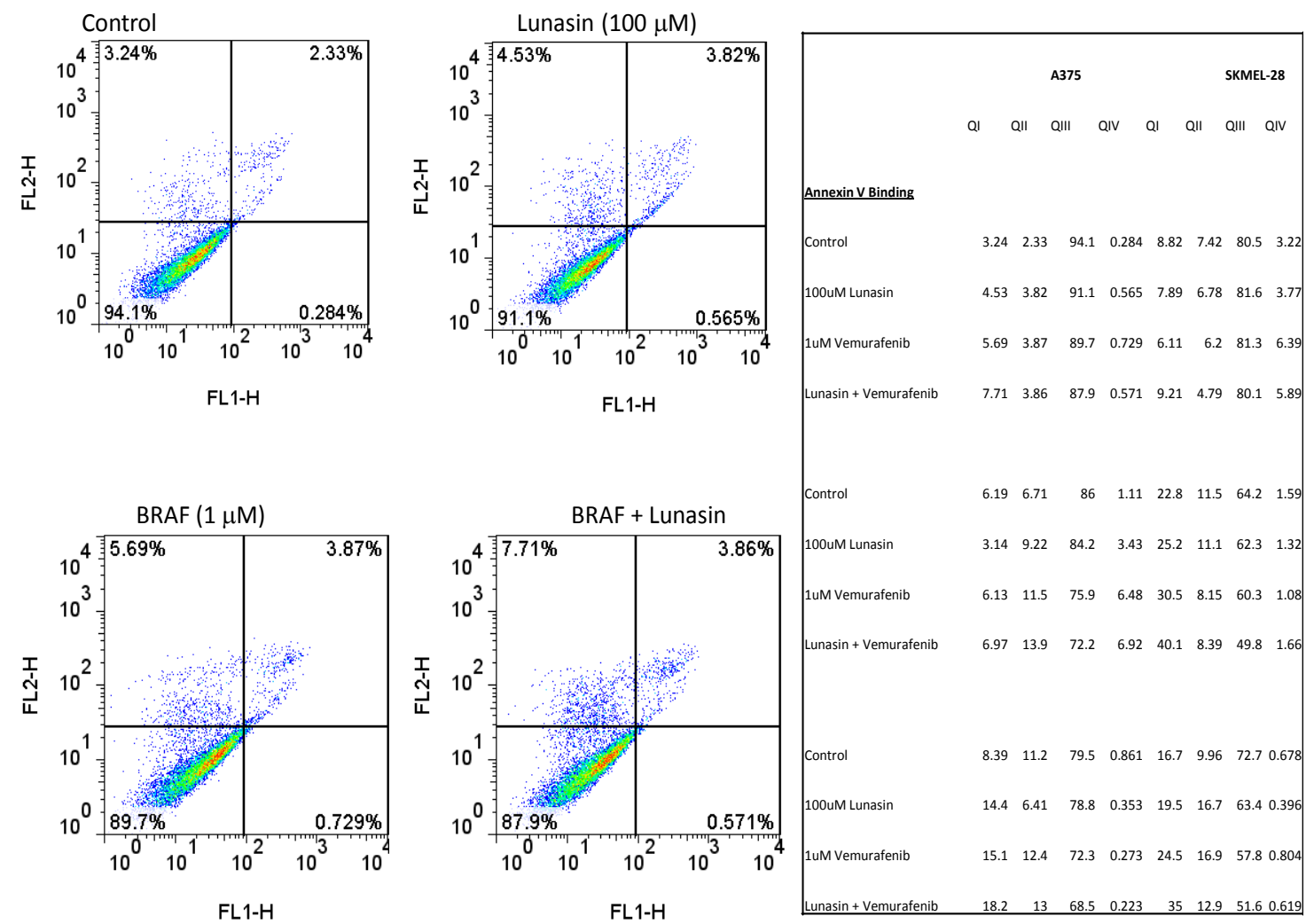

Figure 10: Annexin V binding assays were used to assess apoptotic profiles for A375 and SKMEL-28 melanoma cell lines in response to vemurafenib and lunasin treatments. Lunasin again potentiated the effects of vemurafenib in both cell lines resulting in decreased viability and a concomitant increase in late apoptotic cells. 

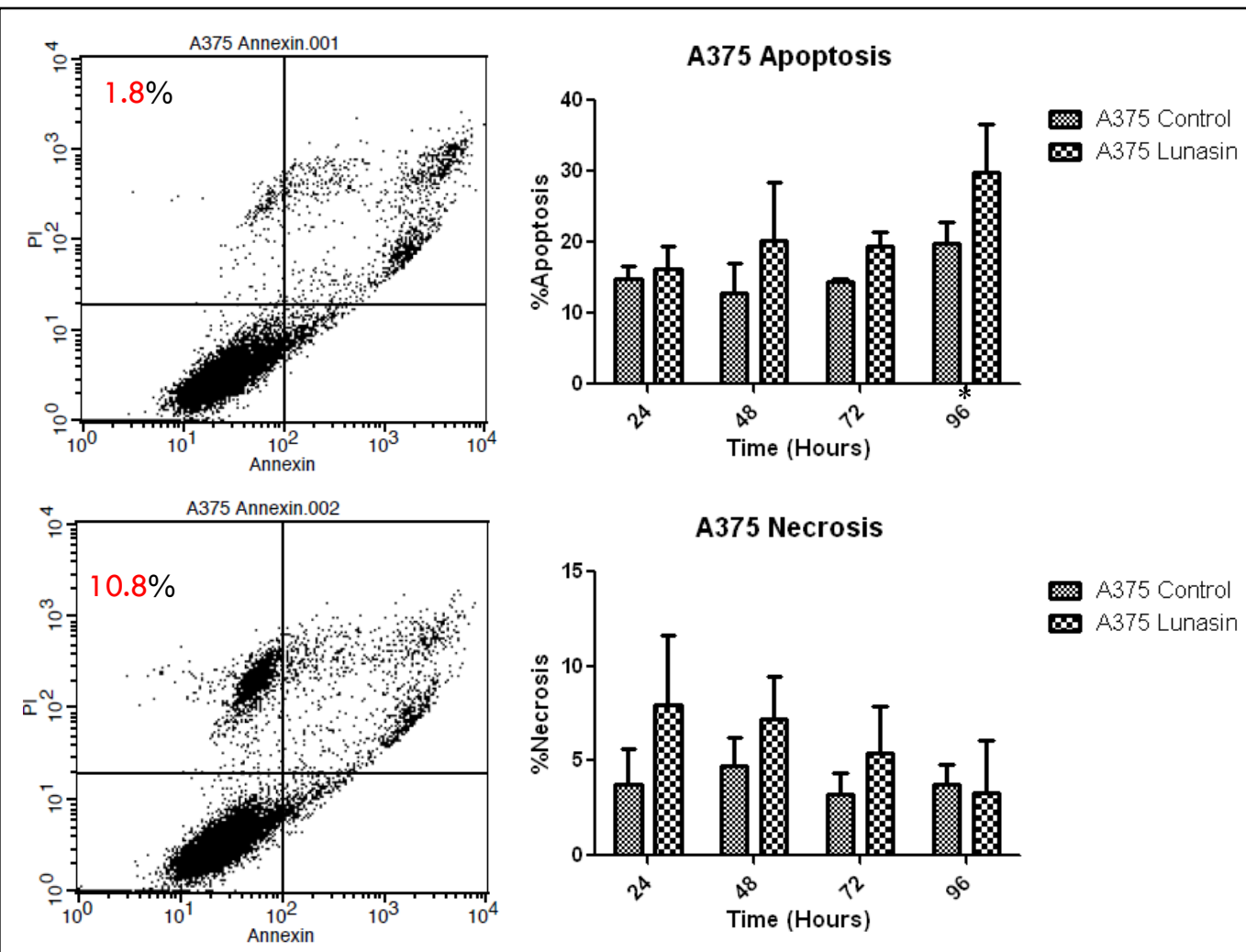

Figure 11: Apoptotic profiles were generated using the Annexin V binding assay. A375 cells treated with $100 \mu \mathrm{M}$ lunasin did not have a significant number of apoptotic cells versus vehicle treated cells until 72 hours. Although significance was not evident, a trend of decreased viability due to lunasin treatment was observed. Significance $(\mathrm{p}<0.05)$ was determined by unpaired Student's T test. 


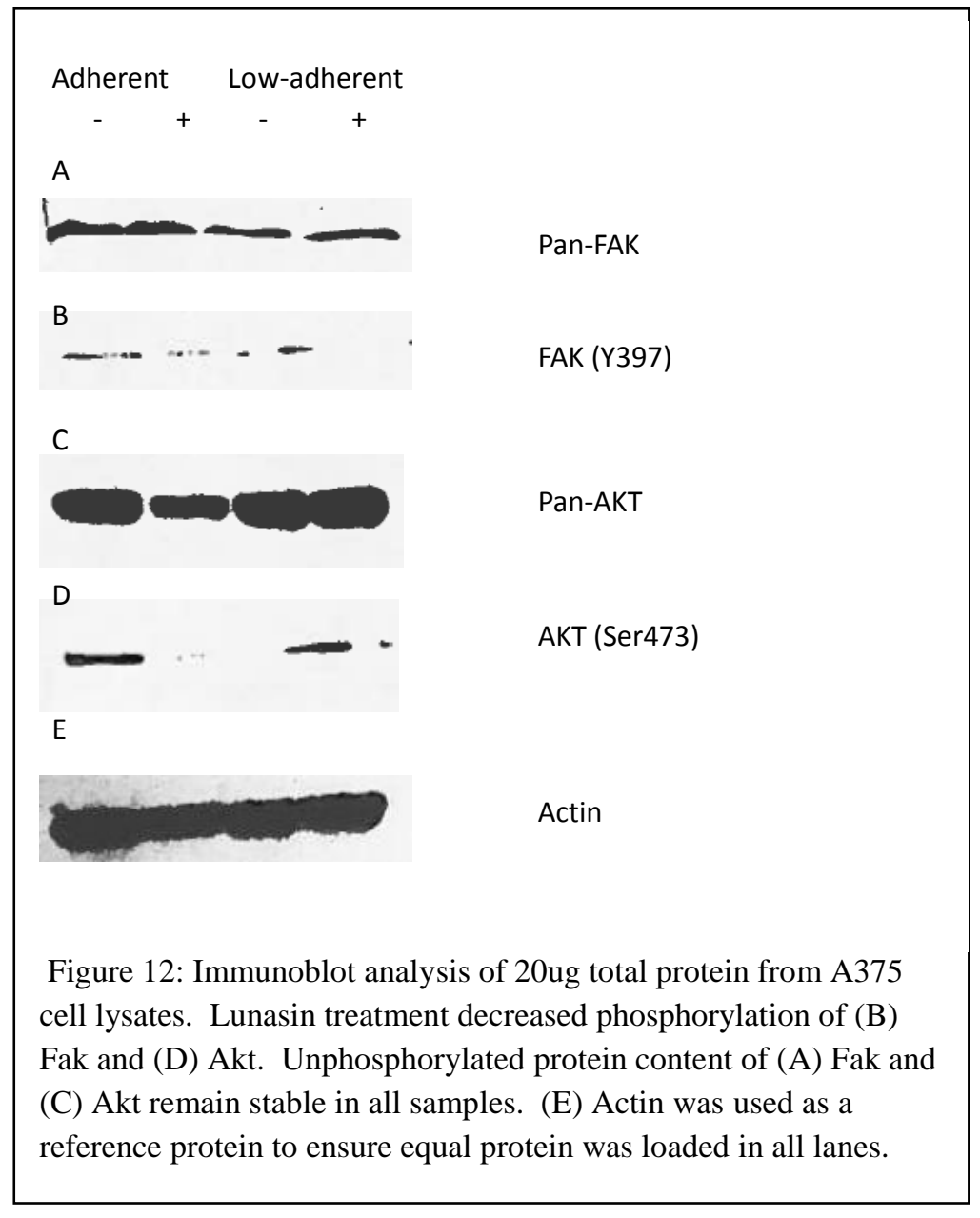




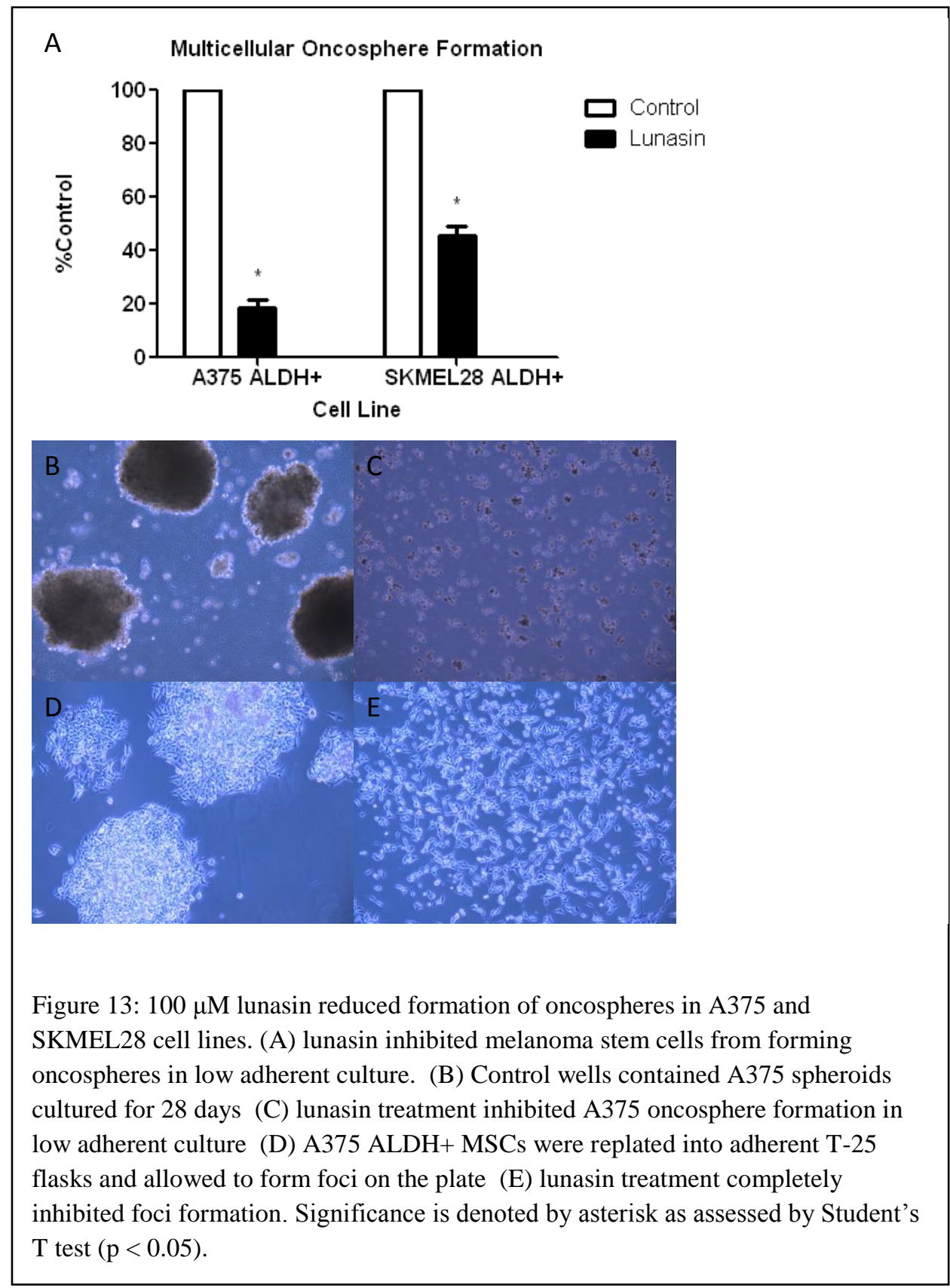




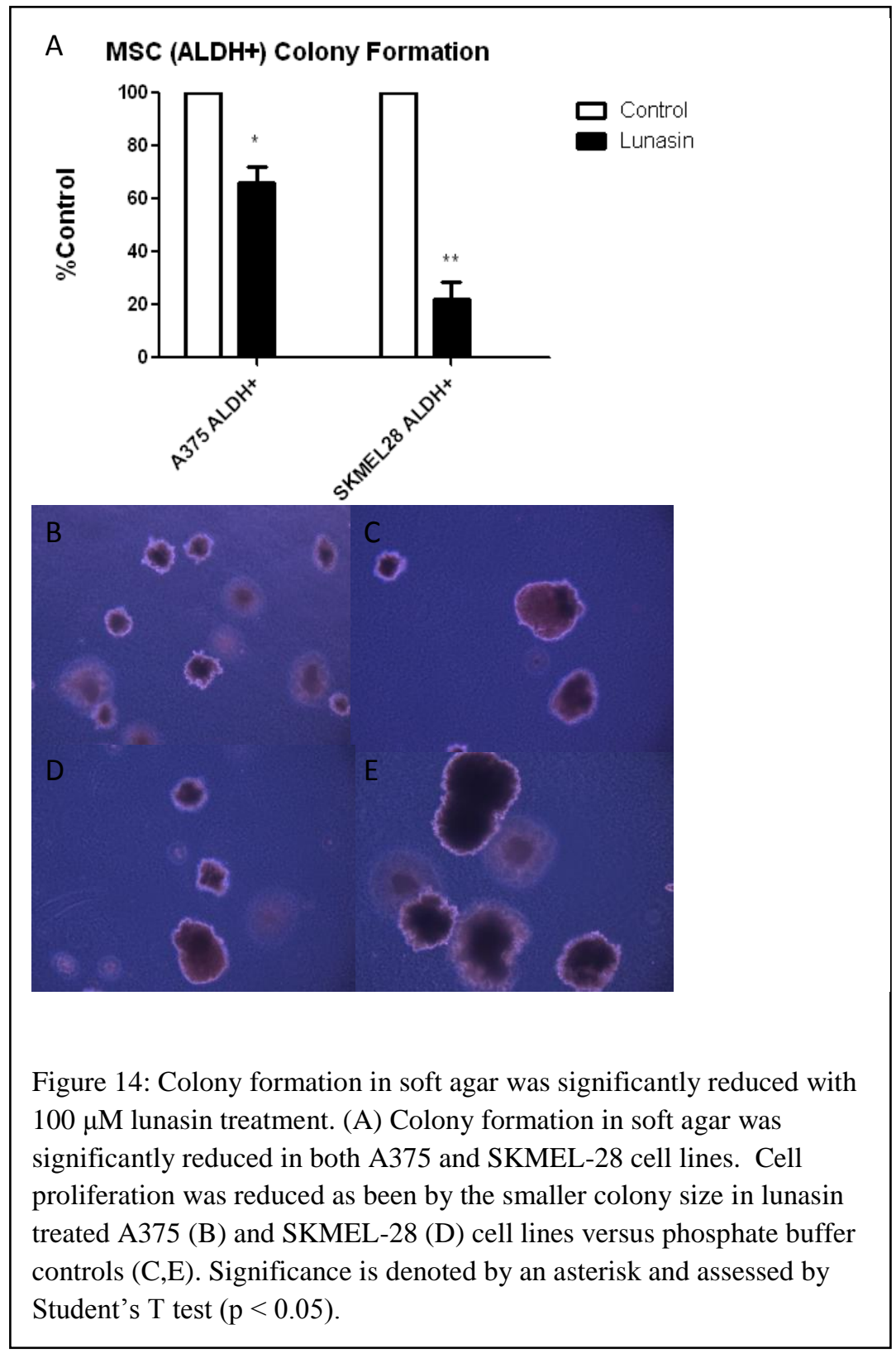



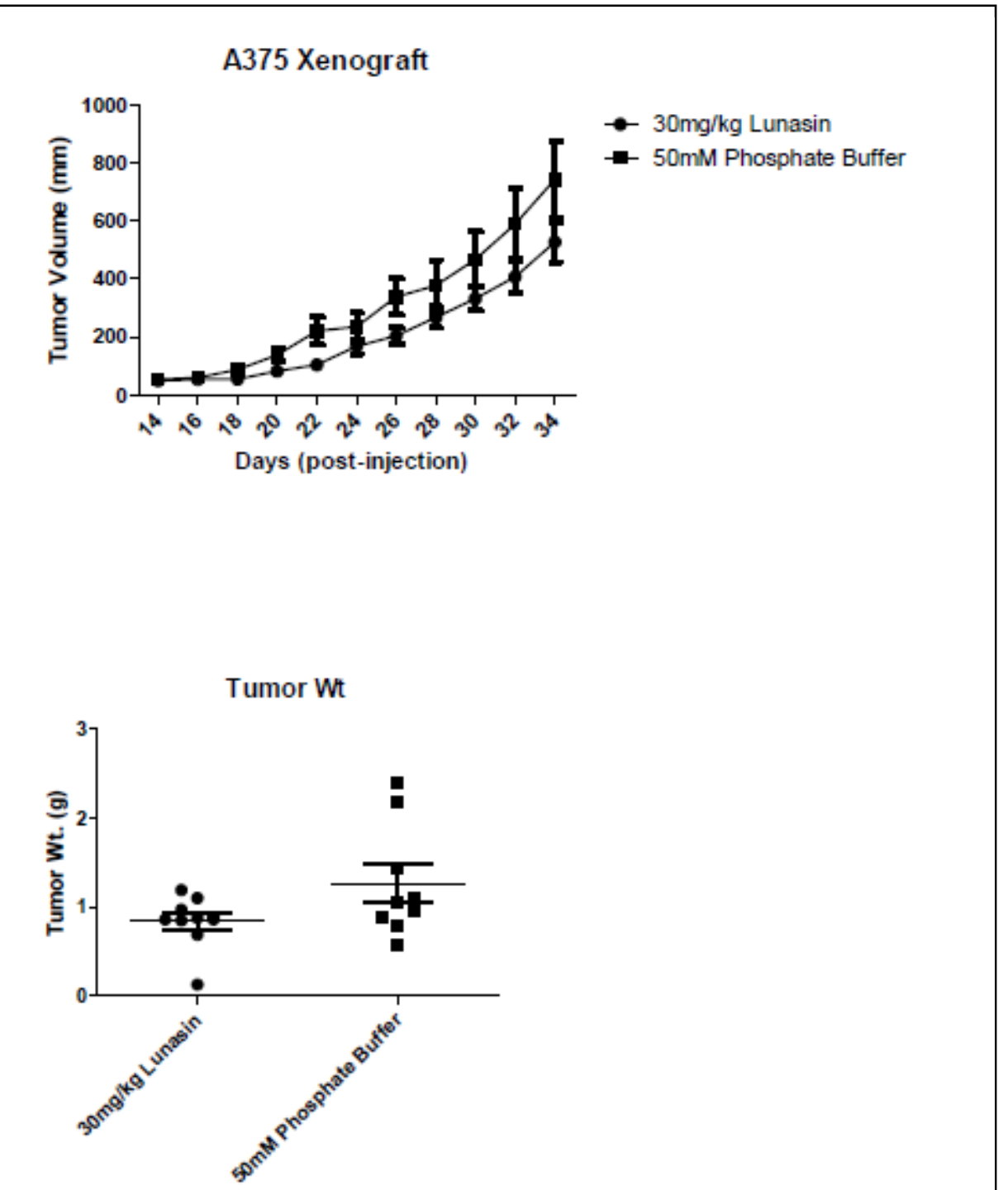

Figure 15: A375 cells formed subcutaneous tumors in nude mice. IV injection of $30 \mathrm{mg} / \mathrm{kg}$ lunasin in athymic nude mice resulted in a $34 \%$ decrease in tumor volume (A) and 35\% decrease in tumor weight versus (B) phosphate buffer treated control mice. Statistical significance was determined by ANOVA $(\mathrm{p}<0.05)$ using GraphPad software analysis. 
A A375 Xenograft Model

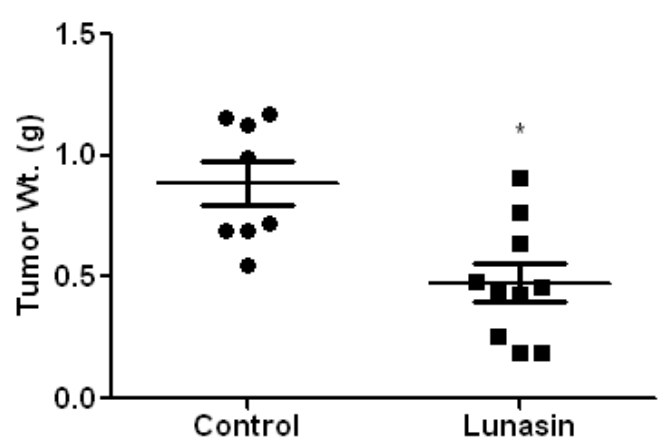

B

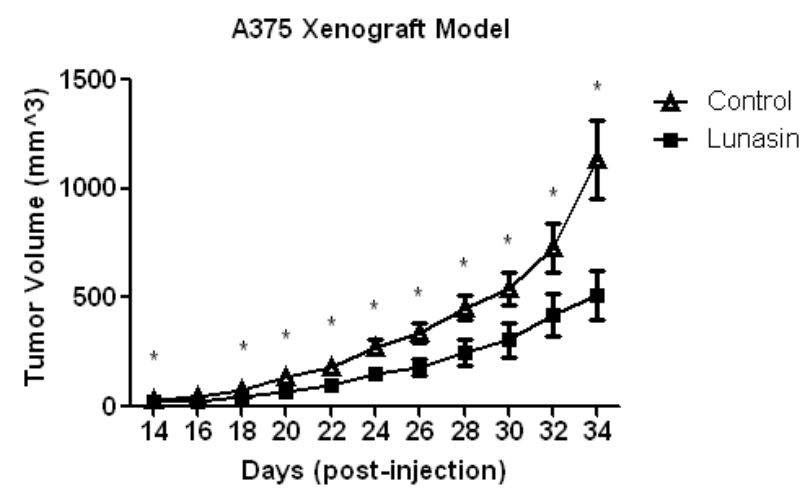

Figure 16: In-vivo xenograft models utilizing athymic nude mice illustrate the potential therapeutic advantage to the soy-derived peptide lunasin. (A) Wet tumor weight from resect tumor tissues. $30 \mathrm{mg} / \mathrm{kg}$ lunasin treatment reduced tumor weights by $46 \%$. (B) Tumor volume was reduced by $55 \%$ and represented a significant difference from phosphate buffer control as determined by one-way ANOVA $(\mathrm{p}<0.05)$ 


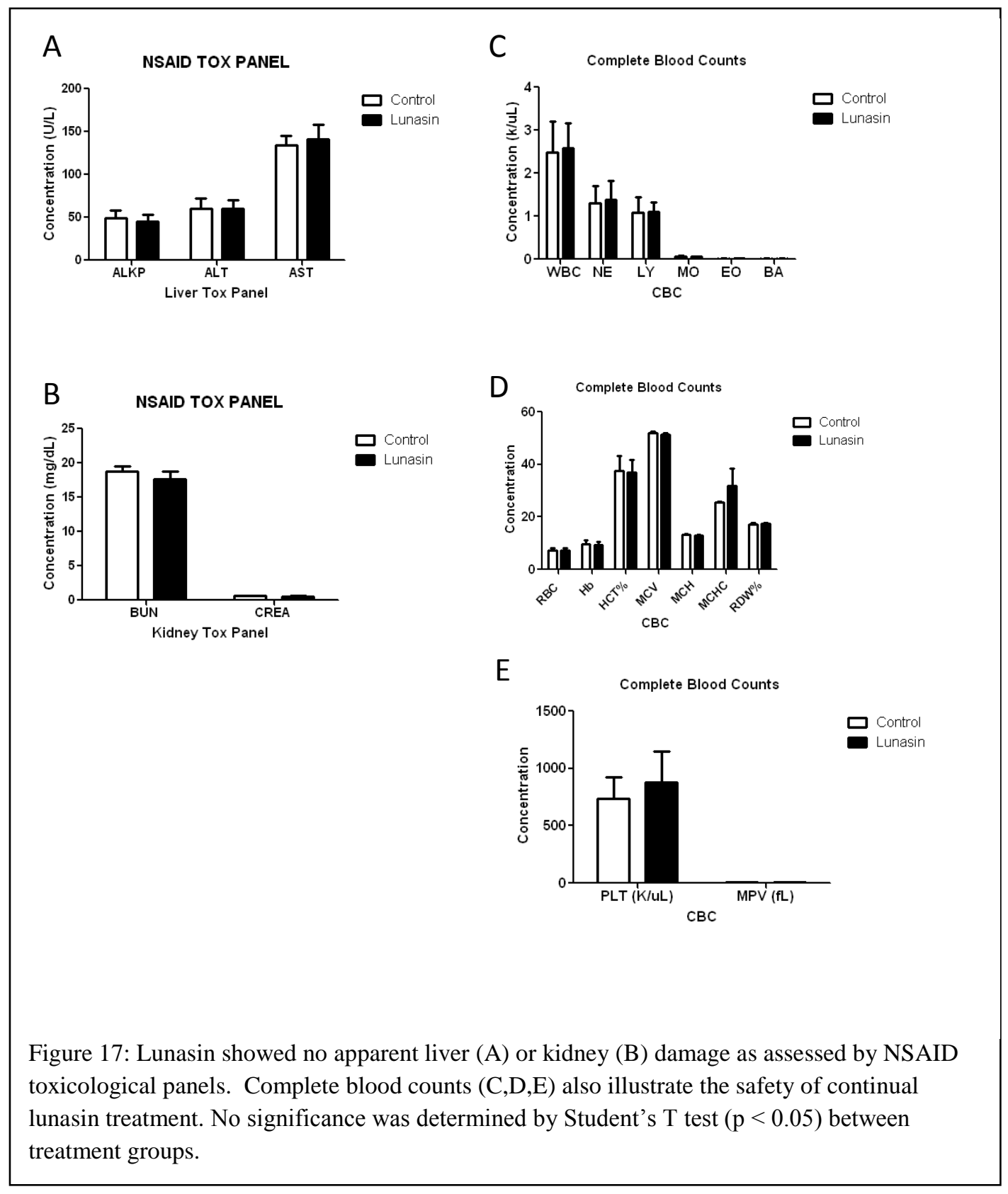



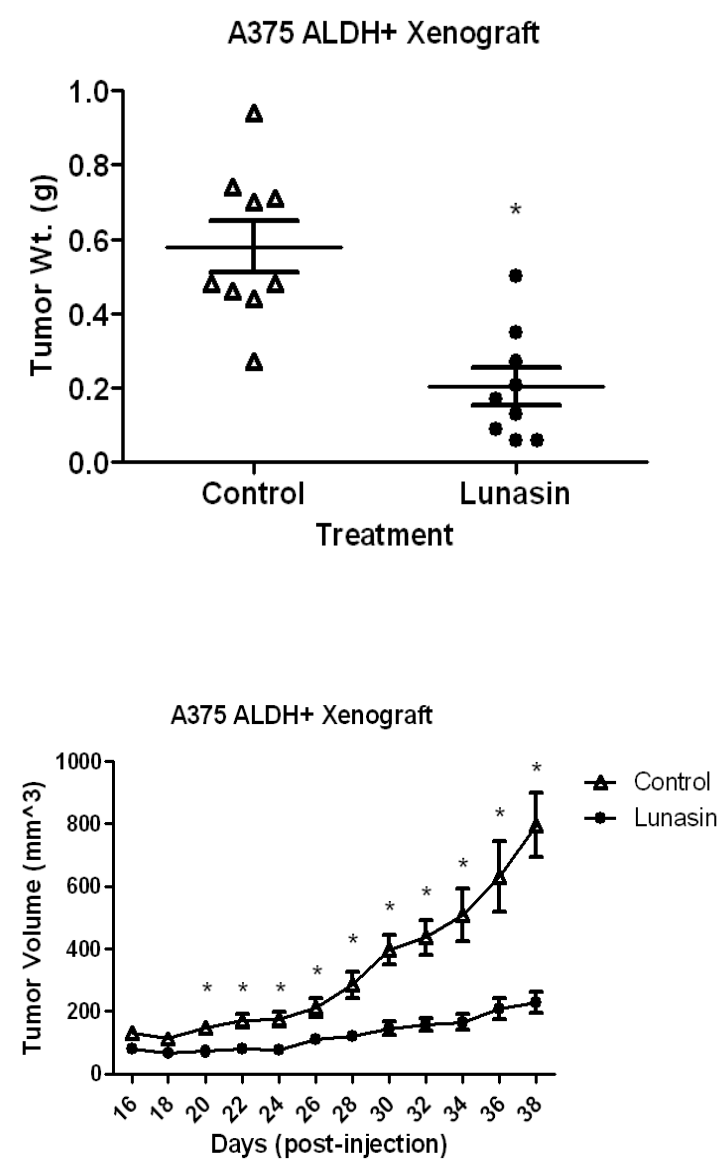

Figure 18: Melanoma stem cell xenograft model (A) $30 \mathrm{mg} / \mathrm{kg}$ lunasin treatment reduced tumor weight by $64 \%$ compared to phosphate buffer control. (B) Tumor volume was also significantly reduced $74 \%$ versus control vehicle. Statistical significance was determined by ANOVA ( $<<$ 0.05) using GraphPad software analysis. 


\section{REFERENCES}

1. Garcia-Nebot, M.J., I. Recio, and B. Hernandez-Ledesma, Antioxidant activity and protective effects of peptide lunasin against oxidative stress in intestinal Caco-2 cells. Food and chemical toxicology : an international journal published for the British Industrial Biological Research Association, 2014. 65: p. 155-61.

2. Cam, A. and E.G. de Mejia, RGD-peptide lunasin inhibits Akt-mediated NF-kappaB activation in human macrophages through interaction with the alphaVbeta3 integrin. Molecular nutrition \& food research, 2012. 56(10): p. 1569-81.

3. Chang, H.C., et al., Soypeptide lunasin in cytokine immunotherapy for lymphoma. Cancer immunology, immunotherapy : Cll, 2014. 63(3): p. 283-95.

4. Hernandez-Ledesma, B., C.C. Hsieh, and B.O. de Lumen, Antioxidant and antiinflammatory properties of cancer preventive peptide lunasin in RAW 264.7 macrophages. Biochemical and biophysical research communications, 2009. 390(3): p. 803-8.

5. Odani, S., T. Koide, and T. Ono, Amino acid sequence of a soybean (Glycine max) seed polypeptide having a poly(L-aspartic acid) structure. The Journal of biological chemistry, 1987. 262(22): p. 10502-5.

6. Seber, L.E., et al., Scalable purification and characterization of the anticancer lunasin peptide from soybean. PloS one, 2012. 7(4): p. e35409.

7. Galvez, A.F., et al., Chemopreventive property of a soybean peptide (lunasin) that binds to deacetylated histones and inhibits acetylation. Cancer research, 2001. 61(20): p. 7473-8.

8. Galvez, A.F. and B.O. de Lumen, A soybean CDNA encoding a chromatin-binding peptide inhibits mitosis of mammalian cells. Nature biotechnology, 1999. 17(5): p. 495-500.

9. Jeong, H.J., Y. Lam, and B.O. de Lumen, Barley lunasin suppresses ras-induced colony formation and inhibits core histone acetylation in mammalian cells. Journal of agricultural and food chemistry, 2002. 50(21): p. 5903-8.

10. de Lumen, B.O., Lunasin: a cancer-preventive soy peptide. Nutrition reviews, 2005. 63(1): p. 16-21.

11. Jeong, H.J., et al., The cancer preventive peptide lunasin from wheat inhibits core histone acetylation. Cancer letters, 2007. 255(1): p. 42-8.

12. Jeong, J.B., et al., Cancer-preventive peptide lunasin from Solanum nigrum L. inhibits acetylation of core histones $\mathrm{H} 3$ and $\mathrm{H} 4$ and phosphorylation of retinoblastoma protein (Rb). Journal of agricultural and food chemistry, 2007. 55(26): p. 10707-13.

13. Omoni, A.O. and R.E. Aluko, Soybean foods and their benefits: potential mechanisms of action. Nutrition reviews, 2005. 63(8): p. 272-83.

14. Lee, M.M., et al., Soy and isoflavone consumption in relation to prostate cancer risk in China. Cancer epidemiology, biomarkers \& prevention : a publication of the American Association for Cancer Research, cosponsored by the American Society of Preventive Oncology, 2003. 12(7): p. 665-8.

15. Messina, M.J., et al., Soy intake and cancer risk: a review of the in vitro and in vivo data. Nutrition and cancer, 1994. 21(2): p. 113-31.

16. Hernandez-Ledesma, B., C.C. Hsieh, and B.O. de Lumen, Lunasin, a novel seed peptide for cancer prevention. Peptides, 2009. 30(2): p. 426-30.

17. Lam, Y., A. Galvez, and B.O. de Lumen, Lunasin suppresses E1A-mediated transformation of mammalian cells but does not inhibit growth of immortalized and established cancer cell lines. Nutrition and cancer, 2003. 47(1): p. 88-94. 
18. Hsieh, C.C., B. Hernandez-Ledesma, and B.O. de Lumen, Lunasin-aspirin combination against NIH/3T3 cells transformation induced by chemical carcinogens. Plant foods for human nutrition, 2011. 66(2): p. 107-13.

19. Avvakumov, N., et al., Conserved molecular interactions within the $\mathrm{HBO}$ acetyltransferase complexes regulate cell proliferation. Molecular and cellular biology, 2012. 32(3): p. 689-703.

20. Santer, F.R., et al., Inhibition of the acetyltransferases $p 300$ and CBP reveals a targetable function for p300 in the survival and invasion pathways of prostate cancer cell lines. Molecular cancer therapeutics, 2011. 10(9): p. 1644-55.

21. Ait-Si-Ali, S., et al., CBP/p300 histone acetyl-transferase activity is important for the $\mathrm{G} 1 / \mathrm{S}$ transition. Oncogene, 2000. 19(20): p. 2430-7.

22. Hernandez-Ledesma, B., C.C. Hsieh, and B.O. de Lumen, Relationship between lunasin's sequence and its inhibitory activity of histones $\mathrm{H} 3$ and $\mathrm{H} 4$ acetylation. Molecular nutrition \& food research, 2011. 55(7): p. 989-98.

23. Hsieh, C.C., B. Hernandez-Ledesma, and B.O. de Lumen, Lunasin, a novel seed peptide, sensitizes human breast cancer MDA-MB-231 cells to aspirin-arrested cell cycle and induced apoptosis. Chemico-biological interactions, 2010. 186(2): p. 127-34.

24. Dia, V.P. and E. Gonzalez de Mejia, Lunasin induces apoptosis and modifies the expression of genes associated with extracellular matrix and cell adhesion in human metastatic colon cancer cells. Molecular nutrition \& food research, 2011. 55(4): p. 62334.

25. Dia, V.P. and E. Gonzalez de Mejia, Lunasin potentiates the effect of oxaliplatin preventing outgrowth of colon cancer metastasis, binds to alpha5beta1 integrin and suppresses FAK/ERK/NF-kappaB signaling. Cancer letters, 2011. 313(2): p. 167-80.

26. Dia, V.P., et al., Structural property of soybean lunasin and development of a method to quantify lunasin in plasma using an optimized immunoassay protocol. Food chemistry, 2013. 138(1): p. 334-41.

27. Cam, A., M. Sivaguru, and E. Gonzalez de Mejia, Endocytic mechanism of internalization of dietary peptide lunasin into macrophages in inflammatory condition associated with cardiovascular disease. PloS one, 2013. 8(9): p. e72115.

28. Playford, M.P. and M.D. Schaller, The interplay between Src and integrins in normal and tumor biology. Oncogene, 2004. 23(48): p. 7928-46.

29. Moro, L., et al., Integrin-induced epidermal growth factor (EGF) receptor activation requires $c$-Src and p130Cas and leads to phosphorylation of specific EGF receptor tyrosines. The Journal of biological chemistry, 2002. 277(11): p. 9405-14.

30. Pu, C.Y., et al., RGD-modified endostatin fragments showed an antitumor effect through antiangiogenesis. Anti-cancer drugs, 2012. 23(8): p. 788-802.

31. Smolarczyk, R., et al., Antitumor effect of RGD-4C-GG-D(KLAKLAK)2 peptide in mouse B16(F10) melanoma model. Acta biochimica Polonica, 2006. 53(4): p. 801-5.

32. Buerkle, M.A., et al., Inhibition of the alpha-nu integrins with a cyclic RGD peptide impairs angiogenesis, growth and metastasis of solid tumours in vivo. British journal of cancer, 2002. 86(5): p. 788-95.

33. Geiger, B., et al., A chimeric N-cadherin/beta 1-integrin receptor which localizes to both cell-cell and cell-matrix adhesions. Journal of cell science, 1992. 103 ( Pt 4): p. 943-51.

34. Howe, A., et al., Integrin signaling and cell growth control. Current opinion in cell biology, 1998. 10(2): p. 220-31.

35. Persad, S., et al., Inhibition of integrin-linked kinase (ILK) suppresses activation of protein kinase B/Akt and induces cell cycle arrest and apoptosis of PTEN-mutant prostate cancer 
cells. Proceedings of the National Academy of Sciences of the United States of America, 2000. 97(7): p. 3207-12.

36. Berthet, V., et al., Role of endoproteolytic processing in the adhesive and signaling functions of alphavbeta5 integrin. The Journal of biological chemistry, 2000. 275(43): p. 33308-13.

37. Fu, G., W. Wang, and B.H. Luo, Overview: structural biology of integrins. Methods in molecular biology, 2012. 757: p. 81-99.

38. Hynes, R.O., Integrins: bidirectional, allosteric signaling machines. Cell, 2002. 110(6): p. 673-87.

39. Berrier, A.L. and K.M. Yamada, Cell-matrix adhesion. Journal of cellular physiology, 2007. 213(3): p. 565-73.

40. Pisano, M., et al., In vitro activity of the alphavbeta3 integrin antagonist RGDechi-hCit on malignant melanoma cells. Anticancer research, 2013. 33(3): p. 871-9.

41. McGary, E.C., D.C. Lev, and M. Bar-Eli, Cellular adhesion pathways and metastatic potential of human melanoma. Cancer biology \& therapy, 2002. 1(5): p. 459-65.

42. Hood, J.D. and D.A. Cheresh, Role of integrins in cell invasion and migration. Nature reviews. Cancer, 2002. 2(2): p. 91-100.

43. Hood, J.D., et al., Differential alphav integrin-mediated Ras-ERK signaling during two pathways of angiogenesis. The Journal of cell biology, 2003. 162(5): p. 933-43.

44. Alavi, A., et al., Role of Raf in vascular protection from distinct apoptotic stimuli. Science, 2003. 301(5629): p. 94-6.

45. Matter, M.L. and E. Ruoslahti, A signaling pathway from the alpha5beta1 and alpha(v)beta3 integrins that elevates bcl-2 transcription. The Journal of biological chemistry, 2001. 276(30): p. 27757-63.

46. Aoudjit, F. and K. Vuori, Integrin signaling inhibits paclitaxel-induced apoptosis in breast cancer cells. Oncogene, 2001. 20(36): p. 4995-5004.

47. Scatena, M., et al., NF-kappaB mediates alphavbeta3 integrin-induced endothelial cell survival. The Journal of cell biology, 1998. 141(4): p. 1083-93.

48. Kuphal, S., R. Bauer, and A.K. Bosserhoff, Integrin signaling in malignant melanoma. Cancer metastasis reviews, 2005. 24(2): p. 195-222.

49. Lee, N., S.R. Barthel, and T. Schatton, Melanoma stem cells and metastasis: mimicking hematopoietic cell trafficking? Laboratory investigation; a journal of technical methods and pathology, 2014. 94(1): p. 13-30.

50. Danen, E.H., et al., Integrin beta 3 cDNA transfection into a highly metastatic alpha $v$ beta 3-negative human melanoma cell line inhibits invasion and experimental metastasis. Biochemical and biophysical research communications, 1996. 226(1): p. 7581.

51. Desgrosellier, J.S. and D.A. Cheresh, Integrins in cancer: biological implications and therapeutic opportunities. Nature reviews. Cancer, 2010. 10(1): p. 9-22.

52. Schatton, T. and M.H. Frank, Antitumor immunity and cancer stem cells. Annals of the New York Academy of Sciences, 2009. 1176: p. 154-69.

53. Schatton, T., et al., Identification of cells initiating human melanomas. Nature, 2008. 451(7176): p. 345-9.

54. Reardon, D.A., et al., Cilengitide: an RGD pentapeptide alphanubeta3 and alphanubeta5 integrin inhibitor in development for glioblastoma and other malignancies. Future oncology, 2011. 7(3): p. 339-54. 
55. (ACS), A.C.S. Skin Cancer Facts. [Online] 2014 3/14/2014 [cited 2014 April 24]; Available from: $\quad$ http://www.cancer.org/cancer/cancercauses/sunanduvexposure/skin-cancer-

facts.

56. Howlader N, N.A., Krapcho M, Garshell J, Miller D, Altekruse SF, Kosary CL, Yu M, Ruhl J, Tatalovich Z,Mariotto A, Lewis DR, Chen HS, Feuer EJ, Cronin KA. SEER Cancer Statistics Review, 1975-2011. 2014 [cited 2014 April 25]; based on November 2013 SEER data submission, posted to the SEER web site, April 2014.]. Available from: http://seer.cancer.gov/csr/1975 2011/.

57. Ji, Z., et al., Vemurafenib synergizes with nutlin-3 to deplete survivin and suppresses melanoma viability and tumor growth. Clinical cancer research : an official journal of the American Association for Cancer Research, 2013. 19(16): p. 4383-91.

58. Trunzer, K., et al., Pharmacodynamic effects and mechanisms of resistance to vemurafenib in patients with metastatic melanoma. Journal of clinical oncology : official journal of the American Society of Clinical Oncology, 2013. 31(14): p. 1767-74.

59. Davies, H., et al., Mutations of the BRAF gene in human cancer. Nature, 2002. 417(6892): p. 949-54.

60. Chapman, P.B., et al., Improved survival with vemurafenib in melanoma with BRAF V600E mutation. The New England journal of medicine, 2011. 364(26): p. 2507-16.

61. Rizos, H., et al., BRAF Inhibitor Resistance Mechanisms in Metastatic Melanoma: Spectrum and Clinical Impact. Clinical cancer research : an official journal of the American Association for Cancer Research, 2014. 20(7): p. 1965-77.

62. Sun, C., et al., Reversible and adaptive resistance to BRAF(V600E) inhibition in melanoma. Nature, 2014. 508(7494): p. 118-22.

63. Nazarian, R., et al., Melanomas acquire resistance to B-RAF(V600E) inhibition by RTK or $N$-RAS upregulation. Nature, 2010. 468(7326): p. 973-7.

64. Tuma, R.S., Getting around PLX4032: studies turn up unusual mechanisms of resistance to melanoma drug. Journal of the National Cancer Institute, 2011. 103(3): p. 170-1, 177.

65. Reya, T., et al., Stem cells, cancer, and cancer stem cells. Nature, 2001. 414(6859): p. 105-11.

66. Clarke, M.F., et al., Cancer stem cells--perspectives on current status and future directions: AACR Workshop on cancer stem cells. Cancer research, 2006. 66(19): p. 933944.

67. Clarke, M.F. and M. Fuller, Stem cells and cancer: two faces of eve. Cell, 2006. 124(6): p. 1111-5.

68. Krivtsov, A.V., et al., Transformation from committed progenitor to leukaemia stem cell initiated by MLL-AF9. Nature, 2006. 442(7104): p. 818-22.

69. Sun, B., et al., The minimal set of genetic alterations required for conversion of primary human fibroblasts to cancer cells in the subrenal capsule assay. Neoplasia, 2005. 7(6): p. 585-93.

70. Fang, D., et al., A tumorigenic subpopulation with stem cell properties in melanomas. Cancer research, 2005. 65(20): p. 9328-37.

71. Monzani, E., et al., Melanoma contains CD133 and ABCG2 positive cells with enhanced tumourigenic potential. European journal of cancer, 2007. 43(5): p. 935-46.

72. Boiko, A.D., et al., Human melanoma-initiating cells express neural crest nerve growth factor receptor CD271. Nature, 2010. 466(7302): p. 133-7.

73. Chaffer, C.L., et al., Normal and neoplastic nonstem cells can spontaneously convert to a stem-like state. Proceedings of the National Academy of Sciences of the United States of America, 2011. 108(19): p. 7950-5. 
74. Quintana, E., et al., Efficient tumour formation by single human melanoma cells. Nature, 2008. 456(7222): p. 593-8.

75. Girouard, S.D. and G.F. Murphy, Melanoma stem cells: not rare, but well done. Laboratory investigation; a journal of technical methods and pathology, 2011. 91(5): p. 647-64.

76. Frank, N.Y., et al., VEGFR-1 expressed by malignant melanoma-initiating cells is required for tumor growth. Cancer research, 2011. 71(4): p. 1474-85.

77. Boonyaratanakornkit, J.B., et al., Selection of tumorigenic melanoma cells using ALDH. The Journal of investigative dermatology, 2010. 130(12): p. 2799-808.

78. Prasmickaite, L., et al., Aldehyde dehydrogenase (ALDH) activity does not select for cells with enhanced aggressive properties in malignant melanoma. PloS one, 2010. 5(5): p. e10731.

79. Luo, Y., et al., ALDH1A isozymes are markers of human melanoma stem cells and potential therapeutic targets. Stem cells, 2012. 30(10): p. 2100-13.

80. Visus, C., et al., Targeting ALDH(bright) human carcinoma-initiating cells with ALDH1A1specific CD8(+) $T$ cells. Clinical cancer research : an official journal of the American Association for Cancer Research, 2011. 17(19): p. 6174-84.

81. Carpentino, J.E., et al., Aldehyde dehydrogenase-expressing colon stem cells contribute to tumorigenesis in the transition from colitis to cancer. Cancer research, 2009. 69(20): p. 8208-15.

82. Ginestier, C., et al., ALDH1 is a marker of normal and malignant human mammary stem cells and a predictor of poor clinical outcome. Cell stem cell, 2007. 1(5): p. 555-67.

83. Dia, V.P. and E.G. Mejia, Lunasin promotes apoptosis in human colon cancer cells by mitochondrial pathway activation and induction of nuclear clusterin expression. Cancer letters, 2010. 295(1): p. 44-53.

84. Pabona, J.M., et al., The soybean peptide lunasin promotes apoptosis of mammary epithelial cells via induction of tumor suppressor PTEN: similarities and distinct actions from soy isoflavone genistein. Genes \& nutrition, 2013. 8(1): p. 79-90.

85. Kapoor, S., Lunasin: attenuating effects on tumour growth in systemic malignancies. Food chemistry, 2014. 150: p. 174.

86. Nagy, T., et al., Mammary epithelial-specific deletion of the focal adhesion kinase gene leads to severe lobulo-alveolar hypoplasia and secretory immaturity of the murine mammary gland. The Journal of biological chemistry, 2007. 282(43): p. 31766-76.

87. Taddei, I., et al., Beta1 integrin deletion from the basal compartment of the mammary epithelium affects stem cells. Nature cell biology, 2008. 10(6): p. 716-22.

88. Golubovskaya, V.M., F.A. Kweh, and W.G. Cance, Focal adhesion kinase and cancer. Histology and histopathology, 2009. 24(4): p. 503-10.

89. Luo, M. and J.L. Guan, Focal adhesion kinase: a prominent determinant in breast cancer initiation, progression and metastasis. Cancer letters, 2010. 289(2): p. 127-39.

90. Hennessy, B.T., et al., Exploiting the PI3K/AKT pathway for cancer drug discovery. Nature reviews. Drug discovery, 2005. 4(12): p. 988-1004.

91. Guan, J.L., Integrin signaling through FAK in the regulation of mammary stem cells and breast cancer. IUBMB life, 2010. 62(4): p. 268-76.

92. $\mathrm{Hu}, \mathrm{Y}$. and L. Fu, Targeting cancer stem cells: a new therapy to cure cancer patients. American journal of cancer research, 2012. 2(3): p. 340-56.

93. Bedogni, B., et al., Notch1 is an effector of Akt and hypoxia in melanoma development. The Journal of clinical investigation, 2008. 118(11): p. 3660-70. 
94. Koch, U. and F. Radtke, Notch and cancer: a double-edged sword. Cellular and molecular life sciences: CMLS, 2007. 64(21): p. 2746-62.

95. Muller, C.S., Notch signaling and malignant melanoma. Advances in experimental medicine and biology, 2012. 727: p. 258-64.

96. O'Connell, M.P. and A.T. Weeraratna, Change is in the air: the hypoxic induction of phenotype switching in melanoma. The Journal of investigative dermatology, 2013. 133(10): p. 2316-7.

97. Hoek, K.S. and C.R. Goding, Cancer stem cells versus phenotype-switching in melanoma. Pigment cell \& melanoma research, 2010. 23(6): p. 746-59.

98. Pinnix, C.C. and M. Herlyn, The many faces of Notch signaling in skin-derived cells. Pigment cell research / sponsored by the European Society for Pigment Cell Research and the International Pigment Cell Society, 2007. 20(6): p. 458-65.

99. Govindarajan, B., et al., Overexpression of Akt converts radial growth melanoma to vertical growth melanoma. The Journal of clinical investigation, 2007. 117(3): p. 719-29.

100. Carreira, S., et al., Mitf regulation of Dia1 controls melanoma proliferation and invasiveness. Genes \& development, 2006. 20(24): p. 3426-39.

101. Cheli, Y., et al., Hypoxia and MITF control metastatic behaviour in mouse and human melanoma cells. Oncogene, 2012. 31(19): p. 2461-70.

102. Cheli, Y., et al., Mitf is the key molecular switch between mouse or human melanoma initiating cells and their differentiated progeny. Oncogene, 2011. 30(20): p. 2307-18.

103. Thurber, A.E., et al., Inverse expression states of the BRN2 and MITF transcription factors in melanoma spheres and tumour xenografts regulate the NOTCH pathway. Oncogene, 2011. 30(27): p. 3036-48. 


\section{CURRICULUM VITAE \\ Christopher P. Shidal \\ 151 Vernon Ave \#2 \\ Louisville, KY 40206 \\ (270) 519-2207 \\ Cpshid01@louisville.edu}

\section{Personal Statement:}

My goals as a research fellow are to define the molecular interactions between specific carcinogens and to characterize the roles of these interactions in the initiation of cancer development. Furthermore, I expect to profile and advance the soy-derived peptide lunasin as a direct chemotherapeutic in melanoma and lung cancers. Previous academic history as well as direct work experiences has provided the basic knowledge and confidence necessary to succeed on these projects. Background experience in the field of pharmacology has allowed me to develop concepts and critical thinking skills necessary to excel throughout my career. While I was an undergraduate at UK, I tested domestic well water samples for coliform and coliphage, which established good laboratory practices and techniques. My time as a quality assurance technician allowed me to demonstrate my ability to work in a group. Furthermore, I was given the opportunity to advance a number of projects independently and in a timely manner. Although it was more geared toward production, my work in quality assurance permitted me to learn a number of wet chemistry protocols and utilize various analytical instruments (i.e. HPLC). This project will sharpen these skills and hopefully become a solid base for future work in the field of pharmacology and toxicology.

\section{Education:}

\begin{tabular}{|lccl|}
\hline INSTITUTION AND LOCATION & $\begin{array}{c}\text { DEGREE } \\
\text { (if } \\
\text { applicable) }\end{array}$ & $\begin{array}{c}\text { DATES } \\
\text { ATTENDED }\end{array}$ & $\begin{array}{c}\text { FIELD OF } \\
\text { STUDY }\end{array}$ \\
$\begin{array}{l}\text { Paducah Community College } \\
\text { (Paducah, KY) }\end{array}$ & N/A & $08 / 04-08 / 05$ & Biology \\
$\begin{array}{l}\text { University of Kentucky } \\
\text { (Lexington, KY) }\end{array}$ & B.S. & $08 / 05-08 / 08$ & Biology \\
$\begin{array}{l}\text { University of Louisville } \\
\text { (Louisville, KY) }(\text { expected })\end{array}$ & M.S. & $08-11$ - Present & Toxicology \\
\hline
\end{tabular}




\section{Positions and Honors:}

Employment

* $2003-2006$

* 2008

$\mathrm{KY})$

* $2008-2010$

$\mathrm{KY})$

* 2011 - present (Louisville, KY)

* 2014 - present
Pharmacy Technician, Lourdes Hospital, (Paducah, KY)

Research Technician, University of Kentucky (Lexington,

Quality Assurance Technician, Air Products (Calvert City,

Predoctoral Researcher, University of Louisville

Visiting Research Associate, Indiana University

$\underline{\text { Volunteerism and Memberships }}$

* 2001 - present

* 2004

* $2008-2011$

* 2011 - present
Volunteer, Relay for Life (Sponsored by ACS)

Volunteer, Habitat for Humanity

Volunteer, ASPCA

Member, Society of Toxicology (SOT)

$\underline{\text { Honors }}$

* 2004-2005

* 2004-2005

* 2009-2010 (Company Award)

* 2011-2013
Academic Scholarship, Paducah Community College

Deans List, Paducah Community College

Governor's Safety and Health Award, Air Products

Graduate Fellowship, University of Louisville (IPIBS)

\section{Publications:}

\section{$\underline{\text { Submitted Abstracts }}$}

Arrowood, Karen, et al. (2008) Characterizing the health risks associated with domestic well water use in rural Western Kentucky leading to an intervention study. University of Kentucky.

Shidal, Chris and Keith R. Davis (2012). Lunasin inhibits proliferation of non-small cell lung cancer (NSCLC) in vitro. Research Louisville, University of Louisville.

Shidal, Chris and Keith R. Davis (2012). Lunasin inhibits proliferation of non-small cell lung cancer (NSCLC) in vitro. J.G. Brown Cancer Center Retreat, University of Louisville.

Shidal, Chris and Keith R. Davis (2013). Molecular intereactions between cadmium and nitrosamine ketone potentiate carcinogenic potential of cigarette smoke. OVSOT 2013 Spring Meeting, University of Louisville. 
Shidal, Chris and Keith R. Davis (2013). Profiling lunasin as an adjuvant treatment in malignant melanoma. J.G. Brown Cancer Center Retreat, University of Louisville $\underline{\text { Presentations }}$

Shidal, Chris (2011). The soy peptide lunasin has antiproliferative effects on non-small cell lung cancer. Departmental seminar, University of Louisville Pharmacology and Toxicology Department.

Shidal, Chris (2012). Lunasin inhibits proliferation of non-small cell lung cancer (NSCLC) in vitro. Research Louisville, University of Louisville.

Shidal, Chris (2012). Lunasin inhibits proliferation of non-small cell lung cancer (NSCLC) in vitro. J.G. Brown Cancer Retreat, University of Louisville.

Shidal, Chris and Keith R. Davis (2013). Molecular intereactions between cadmium and nitrosamine ketone potentiate carcinogenic potential of cigarette smoke. OVSOT 2013 Spring Meeting, University of Louisville.

Shidal, Chris and Keith R. Davis (2013). Profiling lunasin as an adjuvant treatment in malignant melanoma. J.G. Brown Cancer Center Retreat, University of Louisville

Skills:

Cell Culture Work (monolayer and 3D cell cultures, along with cocultures), Assays for Cancer Cell Growth (Soft Agar, Proliferation, Oncosphere Formation), General Lab Protocols (Slide Preparation of Cultured Cells/Tissues, Confocal/Fluorescent Microscopy, Immunoblot, Transient Tranfection of Plasmids, Functional knockdown using siRNA, Flow Cytometry/FACS, GC, Microarray), Animal Work (IV/IP Injections in Mice, Resection of Organ/Tumor Tissues), Statistical Analysis (GraphPad Prism, CalcuSyn, MS Databases) 